\title{
An Experimental Study to Investigate the Micro- Stereolithography Tools for Micro Injection Molding
}

DOI:

10.1108/RPJ-10-2015-0152

Document Version

Accepted author manuscript

Link to publication record in Manchester Research Explorer

\section{Citation for published version (APA):}

Gheisari, R., Da Silva Bartolo, P. J., Goddard, N., \& Domingos, M. (2017). An Experimental Study to Investigate the Micro-Stereolithography Tools for Micro Injection Molding. Rapid Prototyping Journal, 23(4).

https://doi.org/10.1108/RPJ-10-2015-0152

\section{Published in:}

Rapid Prototyping Journal

\section{Citing this paper}

Please note that where the full-text provided on Manchester Research Explorer is the Author Accepted Manuscript or Proof version this may differ from the final Published version. If citing, it is advised that you check and use the publisher's definitive version.

\section{General rights}

Copyright and moral rights for the publications made accessible in the Research Explorer are retained by the authors and/or other copyright owners and it is a condition of accessing publications that users recognise and abide by the legal requirements associated with these rights.

\section{Takedown policy}

If you believe that this document breaches copyright please refer to the University of Manchester's Takedown Procedures [http://man.ac.uk/04Y6Bo] or contact uml.scholarlycommunications@manchester.ac.uk providing relevant details, so we can investigate your claim.

\section{OPEN ACCESS}




\section{Emerald Rapid Prototyping Journal}

An Experimental Study to Investigate the MicroStereolithography Tools for Micro Injection Molding

\begin{tabular}{|r|l|}
\hline Journal: & Rapid Prototyping Journal \\
\hline Manuscript ID & RPJ-10-2015-0152.R2 \\
\hline Manuscript Type: & Original Article \\
\hline Keywords: & $\begin{array}{l}\text { Injection moulding, Layered manufacturing, Microfabrication, Plastics } \\
\text { Industry, Rapid tooling, Stereolithography }\end{array}$ \\
\hline \multicolumn{2}{|c}{} \\
\hline
\end{tabular}

\section{SCHOLARONE ${ }^{m}$}




\title{
An Experimental Study to Investigate the Micro- Stereolithography Tools for Micro Injection Molding
}

\author{
Abstract \\ Purpose - The use of micro stereolithography ( $\mu S L)$ parts as micro injection molding $(\mu \mathrm{IM})$ tools \\ greatly reduces the time and cost to product and offers unique solutions for complex design \\ issues. However, they present challenges to designers because of their strength, thermal \\ characteristics, and shorter lifetimes as compared to other mold materials. In this paper, $\mu S L$ is \\ used to directly build rapid injection mold tools combining micro features for short run \\ production.
}

Design/methodology/approach - In total, three tool inserts were produced. Two different $\mu S L$ mold inserts were produced and evaluated in terms of different build approaches of micro features. One of the inserts includes micro features built horizontally while the other one collaborates features built vertically, both having same geometrical dimensions. To evaluate the replication capability of prototype tools, two different thicknesses were set for micro features i.e. $30 \mu \mathrm{m}$ and $120 \mu \mathrm{m}$. The mold inserts were assembled on a metallic mold frame and tested with Polypropylene (PP).

Findings - It was observed that using inappropriate resin to fabricate the mold inserts can leads to inaccurate geometrical dimensions of the tool. Therefore, the material with high glass transition temperature $\left(T_{g}\right)$ and low thermal conductivity is preferred. Also, the results of this research work showed that the processed material and technology play an important role both on part quality and tool life. After investigating the tool failure mechanisms during the injection, it was observed that tool failure occurred mainly due to excessive flexural stresses and ejection forces during the cavity filling and part ejection phases, respectively.

Originality/value - The paper describes the capability of $\mu S L$ mold inserts for the production of small batches of micro-cantilevers which are used in MEMS relays.

Keywords: Additive Manufacturing, Micro Fabrication, Micro Injection Molding, Micro Stereolithography.

\section{Introduction}

One of the most important aspects of micro-engineering is developing the micro-tool-making capabilities and their constant advances to underpin the product miniaturization trend. These 
technology advances benefit from traditional and new emerging manufacturing processes for prototype, batch, and serial micro-manufacture (Griffiths et al., 2011).

In this context, Additive Manufacturing (AM) technologies have been gaining an increasing importance as they allow for the production of complex geometries with high levels of accuracy and repeatability in a cost effective way. Recent developments in terms of hardware/software and materials has broaden the range of $A M$ applications spanning from high performance industrial components (e.g. automotive, aerospace, etc.) to customized biomedical implants (e.g. scaffolds, prosthesis, etc.) (DeSantis et al., 2015, Domingos et al., 2013). The research reported in this paper investigated the capabilities of AM technologies for the fabrication of micro tools. In particular, the use of AM for fabricating micro tools for injection molding is studied as a potential solution for small batch production of polymer micro parts. To validate the replication capability of the inserts produced by AM techniques, $\mu \mathrm{IM}$ was chosen because it is a cost effective replication method with short cycle times. Generally, tooling steel and other metal alloys are used to produce such inserts (Griffith et al., 2011). However, these days efforts have been put into fabricating them by using engineering polymers; for instance epoxy resins were studied (Jensen et al. 2004, Griffiths et al., 2009). When small batch production with low cost and short lead time is demanded, soft tooling is considered as a potential method. In this regard, AM processes such as stereolithography (SL) can be applied as a rapid tooling solution. Therefore, it could be replaced with conventional tool making technologies (Vasco and Pouzada, 2013).

Concerning the size and accuracy of features, this technology has some limitations. However, the new $\mu S L$ systems have addressed few of limitations. Also, it has been evidenced that limitation can be overcome with the persistent development of this AM technique for producing micro parts. Some publications reported successful use of the $\mu S L$ technique for producing micro gears and micro fluidic devices (Zhang et al., 1999, Maruo and Ikuta, 2002, Yang et al., 2009).

Two general mechanisms of failure in SL tools which occur during injection and ejection stages were studied (Palmer and Colton, 2000). During injection phase features fail due to flow pressure of injected material while within ejection phase the features are taken off from the tool by part. It was found that increased height of features results in low bending resistance. On the other hand, short features are more likely to be failed within ejection phase due to stresses exceeding the yield strength of the resin. Failures occur within injection and ejection phases are 
less compared to each other. Most of the mold failures take place when the part is being ejected due to increased stresses (Huaqing, 2012).

In this study, $\mu S L$ was used to produce mold inserts made of polymer that were validated by $\mu \mathrm{IM}$ for replicating micro cantilevers. Next section describes the experimental setup used to conduct this research. Then, the results of the short-run manufacture of polymer parts using $\mu \mathrm{SL}$ mold inserts are discussed and finally conclusions are made.

\section{Experimental Materials and Methods}

\subsection{Test part design}

The design used to analyze the capabilities of produced mold inserts and the filling behavior of micro cavity under different process conditions is a $23 \mathrm{~mm}$ length $\times 23 \mathrm{~mm}$ width $\times 1 \mathrm{~mm}$ thickness substrate incorporating three cantilevers (see Figure 1). Shorter cantilevers are 4 $\mathrm{mm}$ long, $500 \mu \mathrm{m}$ width and varying thickness from 30 to $120 \mu \mathrm{m}$. Longer cantilever is $8 \mathrm{~mm}$ long, $500 \mu \mathrm{m}$ width and $275 \mu \mathrm{m}$ thick. The design employs $2^{\circ}$ draft angle.

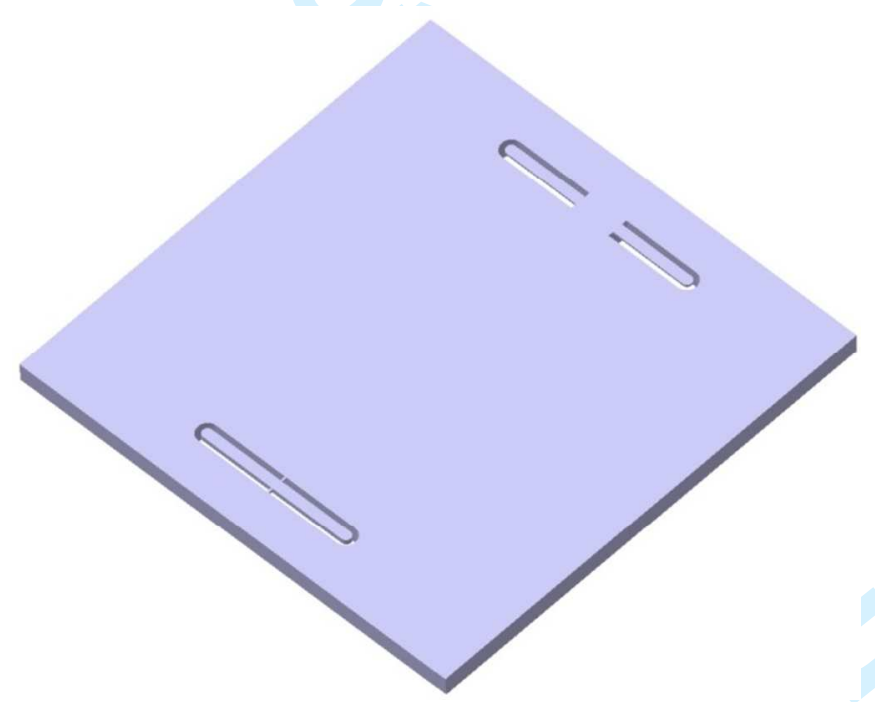

Figure 1. Test part

\subsection{Test material}

A commonly used material in injection molding commercially known as Polypropylene (PP) was applied for moldings as shown in Table 1.

Table 1. Polymer materials properties

\begin{tabular}{ll}
\hline Material & SABIC 56M10 \\
\hline
\end{tabular}




\begin{tabular}{cc}
\hline Category & Polypropylene \\
Structure & Semi-Crystalline \\
Transition temperature & 150 \\
{$\left[{ }^{\circ} \mathrm{C}\right]$} & \\
Ejection temperature $\left[{ }^{\circ} \mathrm{C}\right]$ & 80 \\
Specific heat $[\mathrm{J} / \mathrm{kg}-\mathrm{C}]$ & 2750 \\
Thermal conductivity & 0.18 \\
{$[\mathrm{~W} / \mathrm{m}-\mathrm{C}]$} & 481 \\
\hline Shear modulus $[\mathrm{MPa}]$ & \\
\hline
\end{tabular}

\subsection{Mold manufacture}

The mold considered in this research is a hybrid mold with a metallic frame fabricated using conventional CNC machines i.e. Mikron HSM 400 and DATRON CAT3D_M6. Polymeric mold inserts were produced using the micro stereolithography system ProJet 1200 from 3D systems by commercial material known as VisiJet FTX Green (see Table 2).

Table 2. Properties of the material used for producing mold inserts

\begin{tabular}{ll}
\hline Material & VisiJet FTX Green \\
\hline Colour & Dark Green \\
Density $\left(25^{\circ} \mathrm{C}\right)$ & $1.04 \mathrm{~g} / \mathrm{cm}^{3}$ \\
Tensile Strength & $30 \mathrm{MPa}$ \\
Tensile Modulus & $1700 \mathrm{MPa}$ \\
Flexural Stress & $40 \mathrm{MPa}$ \\
\hline
\end{tabular}

Three inserts with layer thickness of $30 \mu \mathrm{m}$ were considered for investigations in terms of mold quality and replication capabilities:

- Insert 1: $30 \mu \mathrm{m}$ thickness of shorter cantilevers;

- Insert 2: $120 \mu \mathrm{m}$ thickness of shorter cantilevers;

- Insert 3: $120 \mu \mathrm{m}$ thickness of shorter cantilevers;

All the mold inserts had identical dimensions (excluding the thickness of shorter cantilevers). It is worthwhile to point out that insert 3 was only used to assess the quality of tools produced by $\mu \mathrm{SL}$ and no experiment was carried out on it. Each insert includes features identified as C1, C2 and C3 as indicated in Figure 2. To increase the tool mechanical stiffness, hardness and 
precise tool alignment a modular steel mold base was designed with nominal dimensions of $75.2 \mathrm{~mm}$ length $\times 75.2 \mathrm{~mm}$ width $\times 92 \mathrm{~mm}$ height. The inserts were fitted into an aluminum insert holder supported by a steel bolster. Figure 3 shows two halves of the mold.

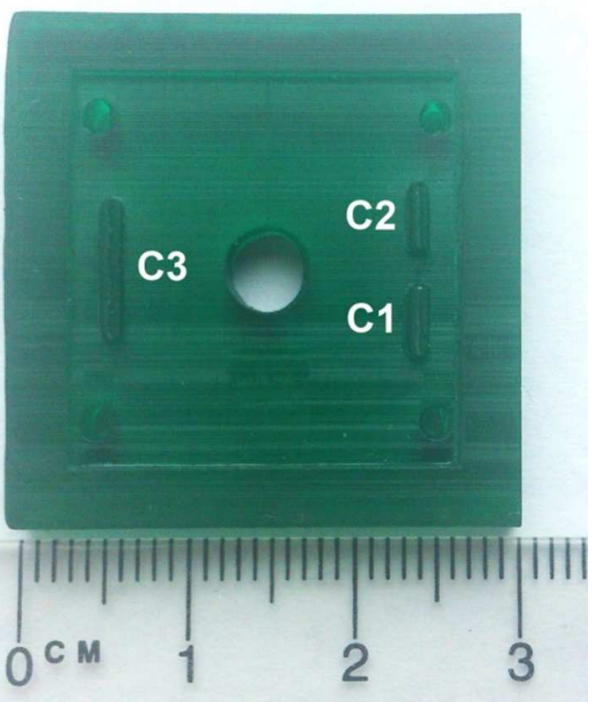

Figure 2. Mold insert fabricated by $\mu \mathrm{SL}$ technique including three micro cantilevers marked as $\mathrm{C} 1, \mathrm{C} 2$ and $\mathrm{C} 3$
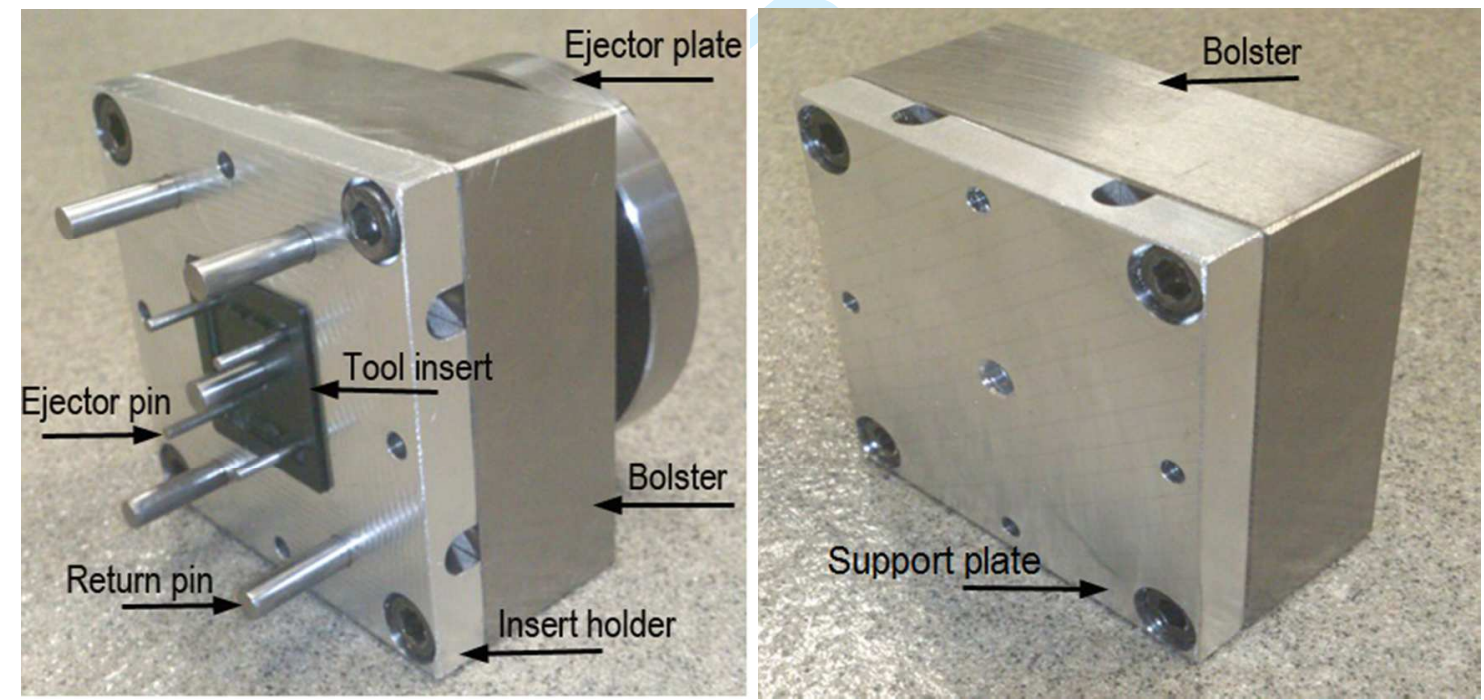

Figure. 3 Mold halves: moving half (left) and fixed half (right)

\section{Results and Discussion}

\subsection{The quality of $\mu S L$ mold inserts}


The quality of inserts fabricated by $\mu S L$ is critical for successful performance in polymer replication. There are three micro features inside the cavity that can determine the quality of fabricated tools. Therefore, the assessment would be based on their geometrical accuracy. The build orientation of all the inserts was vertical; however, two different build approaches were applied to produce them. In the first approach micro features were in horizontal position while in the second approach they were in vertical position. As it is indicated in Figure 4, insert 2 and 3 with different features orientation were compared. This allowed us to assess the effect of features position on the build quality. After analysis of the results, it was observed that the features built in vertical position benefit from higher accuracy comparing to those built in horizontal position.
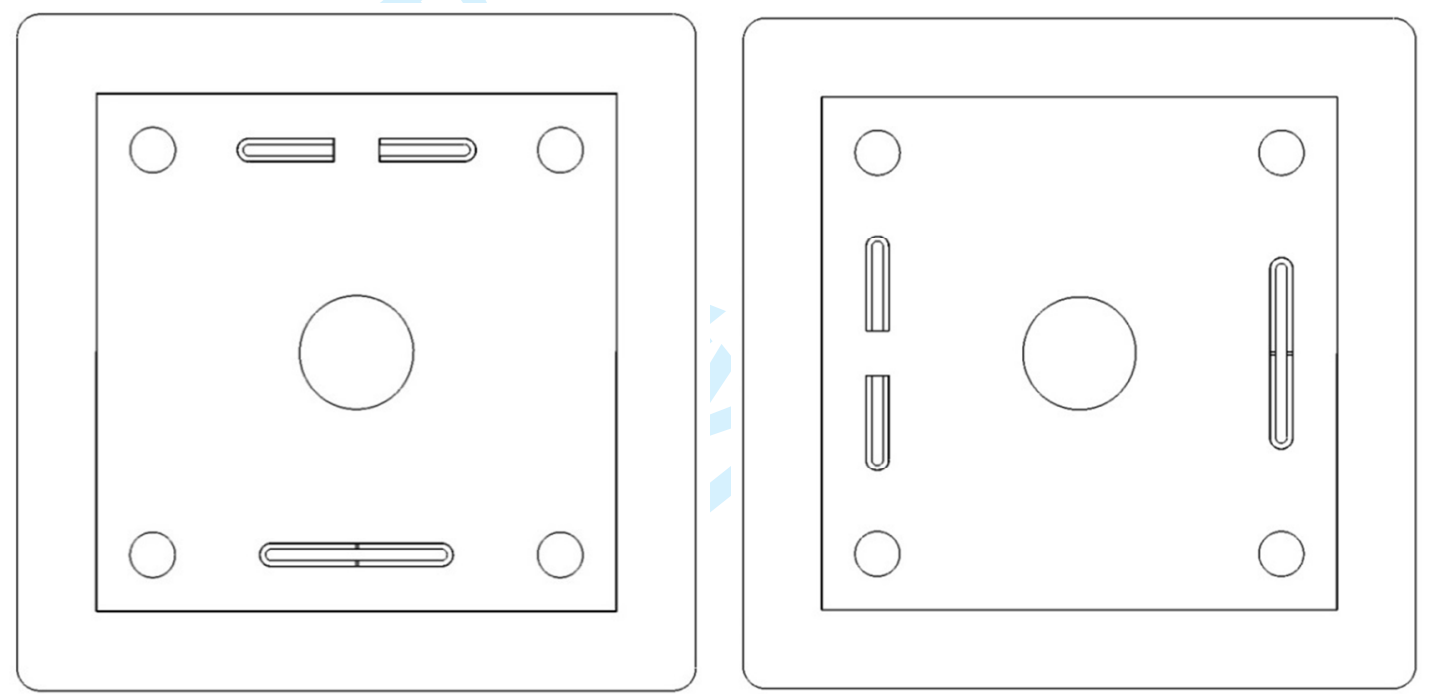

Figure 4. Insert 2 with features built horizontally (left) and insert 3 with features built vertically (right)

The vertical resolution of SL process depends on the polymerised thickness of the created layers. In other words, it is not dependent on the thickness of liquid resin layer spread on the surface of the part. Also, the light will penetrate deep in the chemical medium if it is not restricted to the surface of component being built which leads to parasitic polymerisation in the regions that are already polymerised. The main parameters which have to be taken into account for the improvement of the vertical resolution of $\mu S L$ are the light penetration in the resin and the control of the polymerization depth.

If these parameters are not controlled, the z-overcure error occurs which refers to the solidification of a certain amount of excessive material below the layer being built, due to the penetration of light across the layers which are already polymerised (it is known as print-through 
in $\mathrm{SL}$ ). This error is basically known as the source of inaccuracy in vertical orientation. It also can have tremendous influence on the degradation of material and leads to unwanted polymerizations that can cause deformation of the features as indicated in Figures 5.

This phenomenon usually occurs when the resin is irradiated close to the polymerization threshold or when resins with low reactivity and absorption are used. In fact, when the first layer of an overhanging structure is built, the resin underneath is sensitized but it is not polymerized as the threshold energy has not been reached locally.
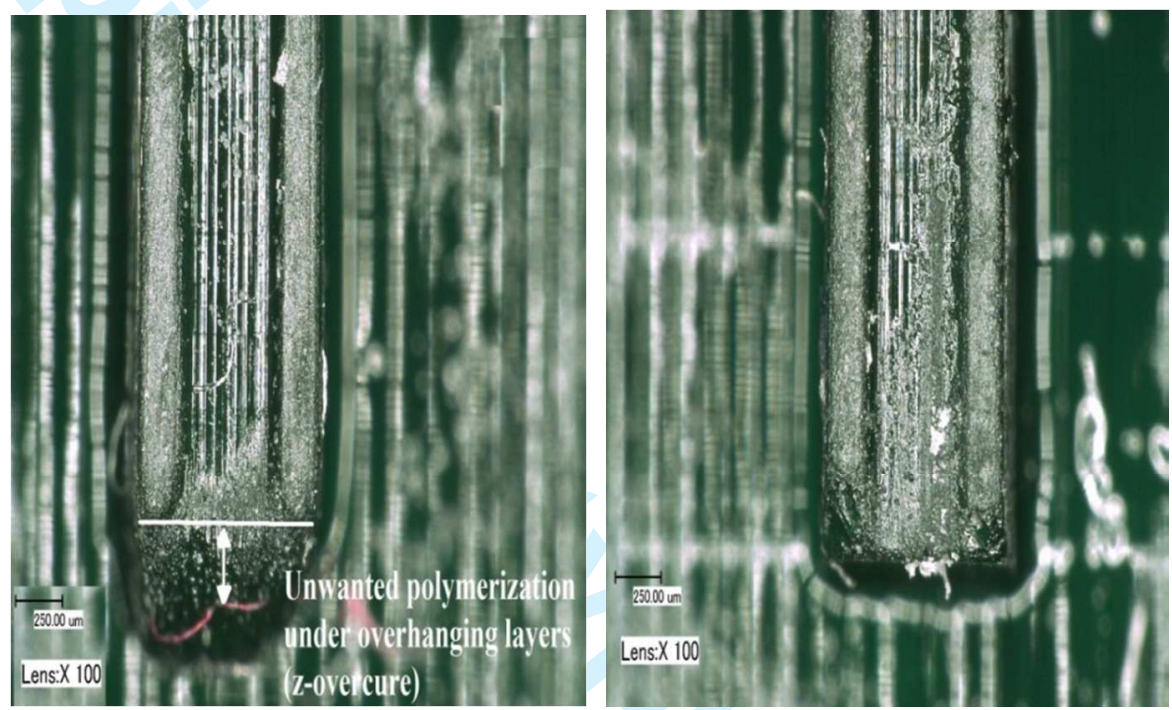

Figure 5. Comparison of channels with unwanted polymerization (left) and without it (right)

As photoinitiation is a cumulative process, this already sensitized region absorbs more energy when more layers are spread on top of the overhanging area. Therefore, the energy reaches the threshold which leads to the start of polymerization and finally results in very large changes of the polymerized thickness, makes it impossible to control the polymerization process accurate and the creation of unwanted polymer structure (Rahmati and Dickens, 2007).

One solution to aforementioned problems in vertical resolution of micro features can be the modification of the photosensitive resins used to decrease the light penetration in chemical media. On the other hand, when the micro features are in the horizontal position, controlling the thickness of liquid layer deposited on the previous layer will be difficult. It is due to the increased effect of gravity forces intervene the leveling of the surface after the deposition of fresh liquid on top of the part being built (see Figure 6). Therefore, the rheological properties of the resin are crucial in order to achieve high resolution features. 

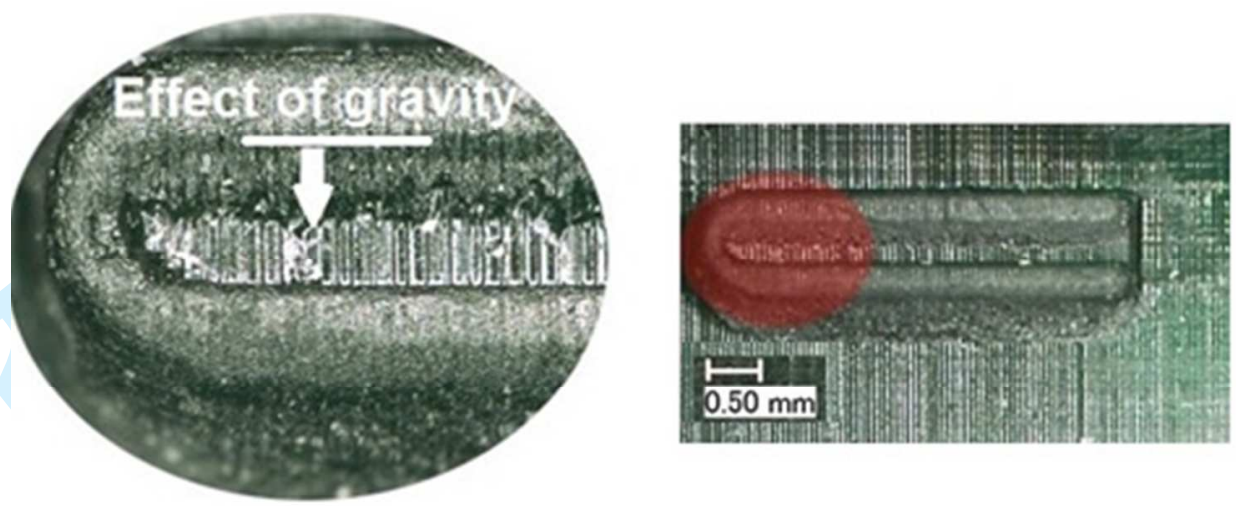

Figure 6. Increased effect of gravity in micro features built horizontally

It was observed that the flow paths of feature C3 in insert 3 are almost blocked which led to incomplete filling of the cavity (see Figure 7). As it was mentioned earlier, it is due to vertical build orientation which results in z-overcure error.
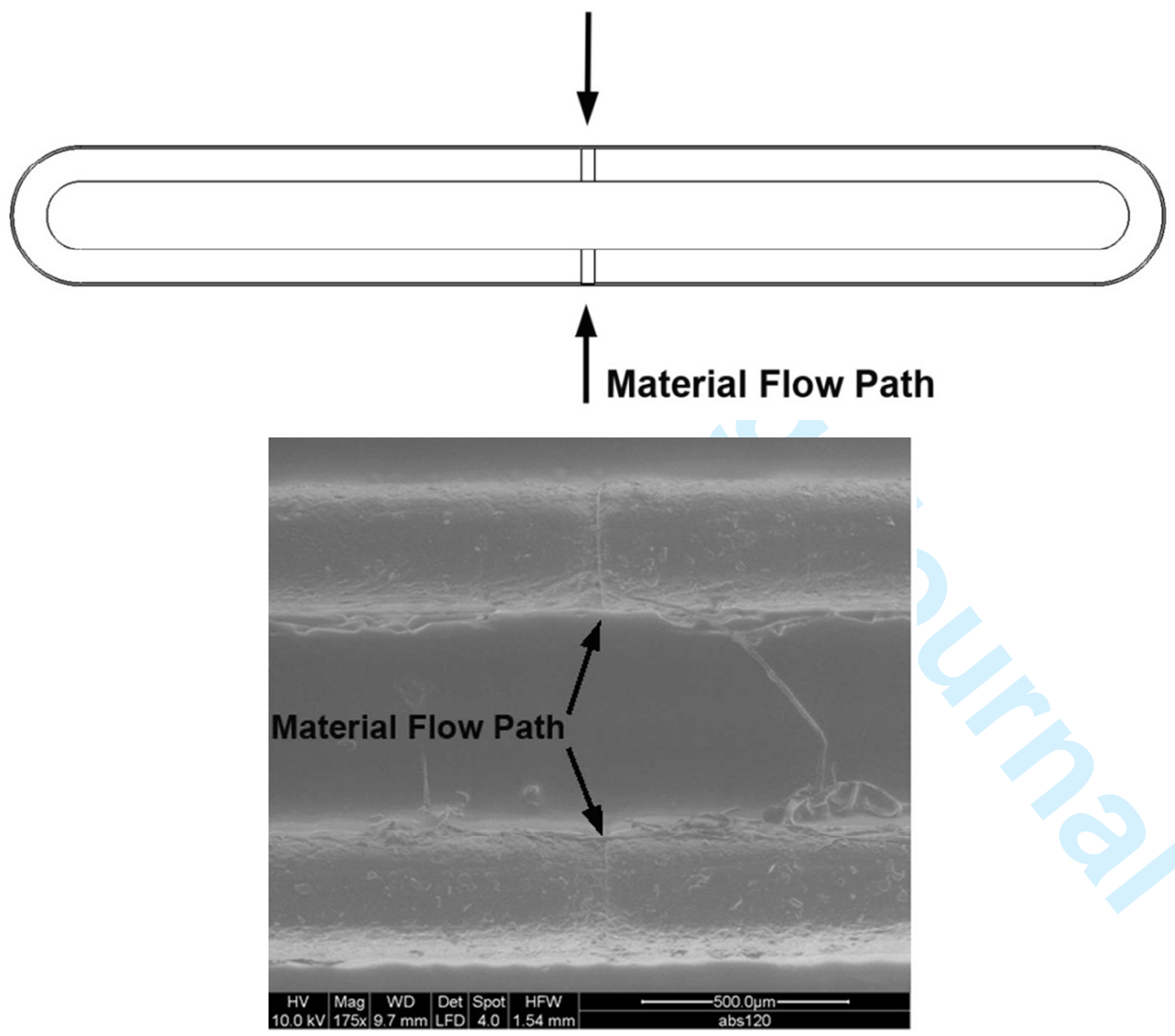

Figure 7. Flow paths of C3 inside insert 3, sketch of micro feature (top) and SEM image of micro feature (bottom) 
To investigate the geometrical accuracy of the produced mold inserts, the channels $\mathrm{C} 1, \mathrm{C} 2$ and C3 were inspected in each insert by using an optical microscope. Five measurements were taken in each feature so that 15 measurements were taken for each mold insert. The mean results presented in Figures 8 and 9 depicts that the features depth and width in each mold insert were not the same. In the case of $\mathrm{C} 1$ and $\mathrm{C} 2$, the mean depth values ranges from 95.06 to 93.44 and from 77.98 to 87.26 for insert 2 and insert 3 , respectively, while in the case of $C 3$ it was 152.28 and 190.64. The mean width values range from 437.44 to 456.48 and from 552.2 to 503.26 for insert 2 and insert 3 , respectively. One of the possible reasons for this variation can be improper calibration of the machine and/or human/machine error while measuring the objects. Moreover, as it was discussed above the rheological properties of the resin material could be a potential reason for the obtained results which imply a more suitable resin for producing mold inserts should be applied.

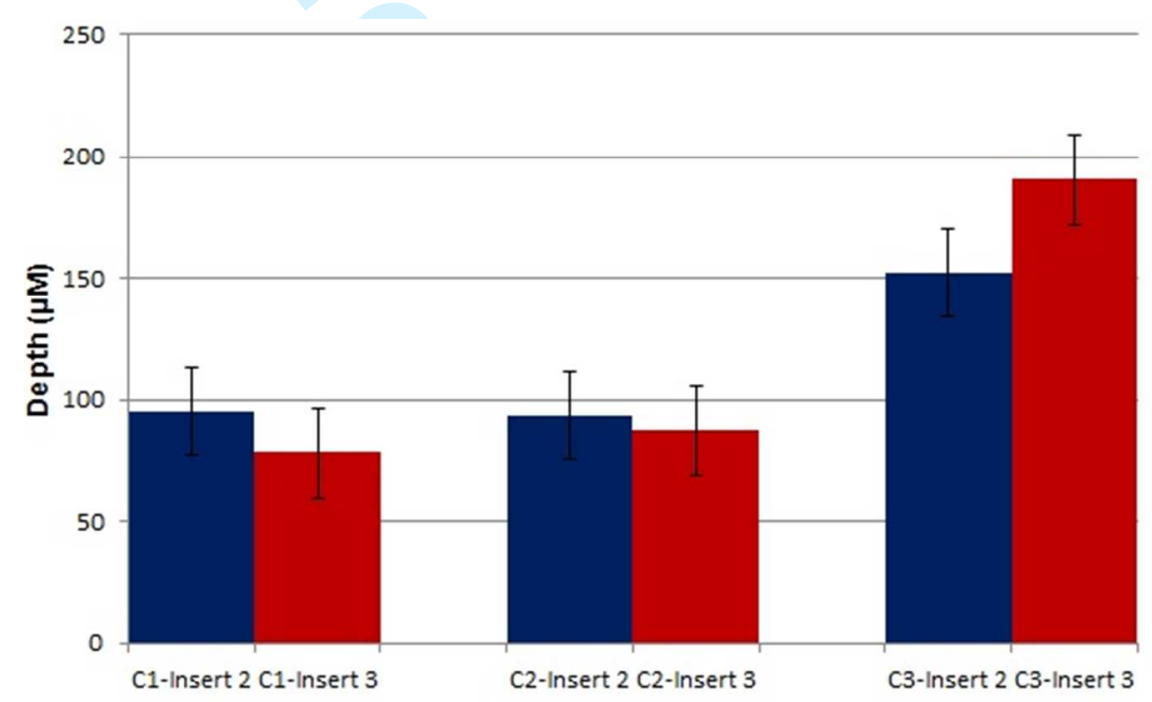

Figure 8. Depth measurements of micro features in insert 2 and insert 3 


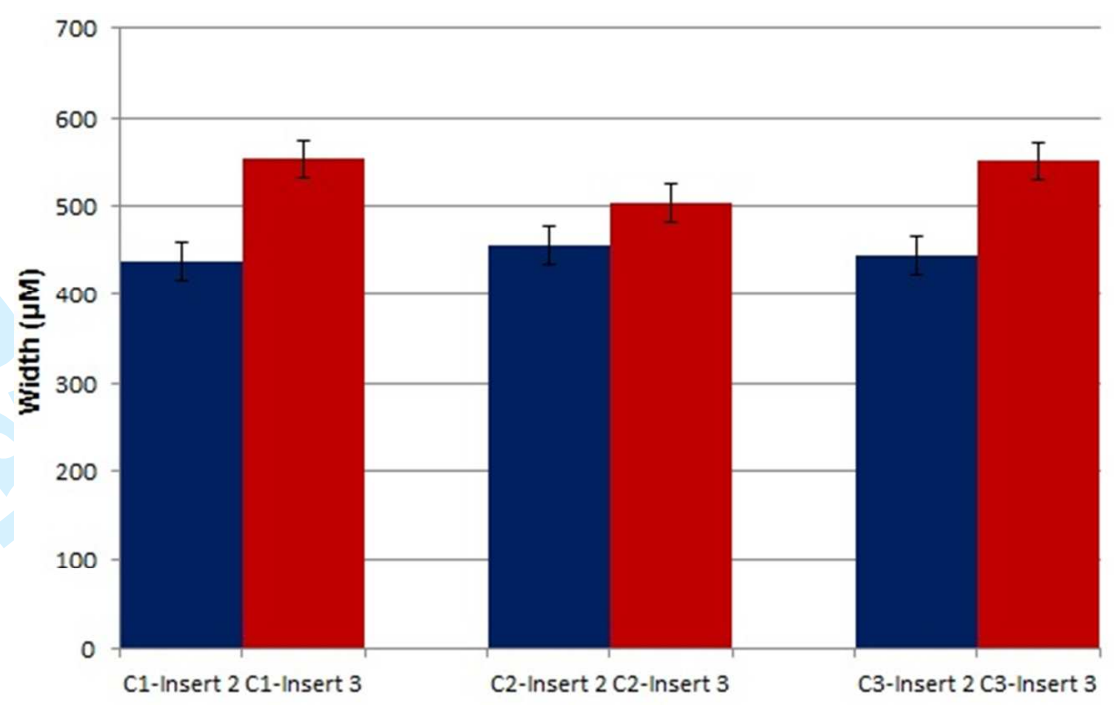

Figure 9. Width measurements of micro features in insert 2 and insert 3

\subsection{Replication capability of $\mu \mathrm{SL}$ mold inserts}

To study the capabilities of the $\mu S L$ insert as a viable option for $\mu \mathrm{IM}$, polymer parts were replicated with each mold insert. By using the optimized settings presented in Table 3 , the experiments were carried out. In this study, no mold temperature was adjusted due to low strength of the material used for producing inserts. On the other hand, mold temperature only would be significant in the process if it is kept enough high (close to the melt temperature) so that facilitates the melt flow. Otherwise, it would not have any significant effect on the process.

Two sets of experiments were implemented by insert 1 and insert 2. For each of the tool inserts five parts were molded until the micro features failed. The micro features in the cavity were examined before and after the experiments, and the parts were also inspected to assess the replication quality.

Table 3. Molding settings

\begin{tabular}{|c|c|c|c|c|}
\hline \multirow{2}{*}{ Test } & \multirow{2}{*}{ Material } & \multicolumn{3}{|c|}{ Process settings } \\
\hline & & $\begin{array}{l}\text { Melt temperature } \\
{\left[{ }^{\circ} \mathrm{C}\right]}\end{array}$ & Injection time [s] & $\begin{array}{l}\text { Thickness of } \\
\text { features }[\mu \mathrm{m}]\end{array}$ \\
\hline Insert 1 & PP & 270 & 1 & 30 \\
\hline Insert 2 & PP & 270 & 1 & 120 \\
\hline
\end{tabular}

For insert 1, the failure in micro features started during the third replication and eventually the tool was entirely damaged within fifth molding. Although the features $\mathrm{C} 1$ and $\mathrm{C} 2$ were filled 
during the third molding (see Figure 10), the observations showed that the reason behind filling was failing the tool in a ductile manner. The molten material heated the tool above its glass transition temperature $\left(\mathrm{T}_{\mathrm{g}}\right)$ and flowed into the channels by taking off the features slightly.

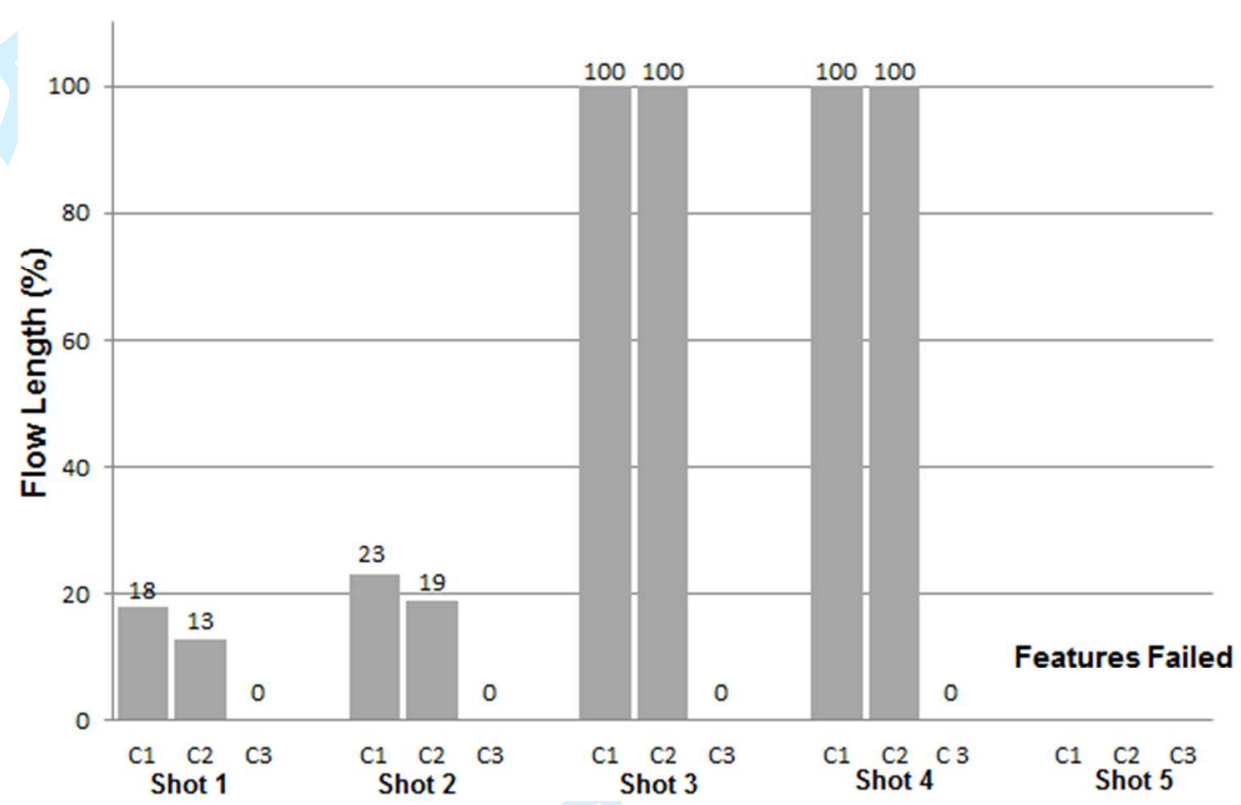

Figure 10. The achieved flow length after each replication with insert 1

In other words, the normal melt temperature for injection molding exceeds $200{ }^{\circ} \mathrm{C}$ while SL materials have a $\mathrm{T}_{\mathrm{g}}$ of approximately $75^{\circ} \mathrm{C}$. Therefore, when the material is injected into the cavity, it causes the mold to be heated above its $T_{g}$ within the cavity filling which affects the mold durability, in particular when the injection time is increased. In fact, SL resin is weakened with increase in cavity temperature where the injection pressure is beyond the tool strength. Hence, the instantaneous strength of the insert and its features is less than the injection pressure which results in features failure as shown in Figures 11.
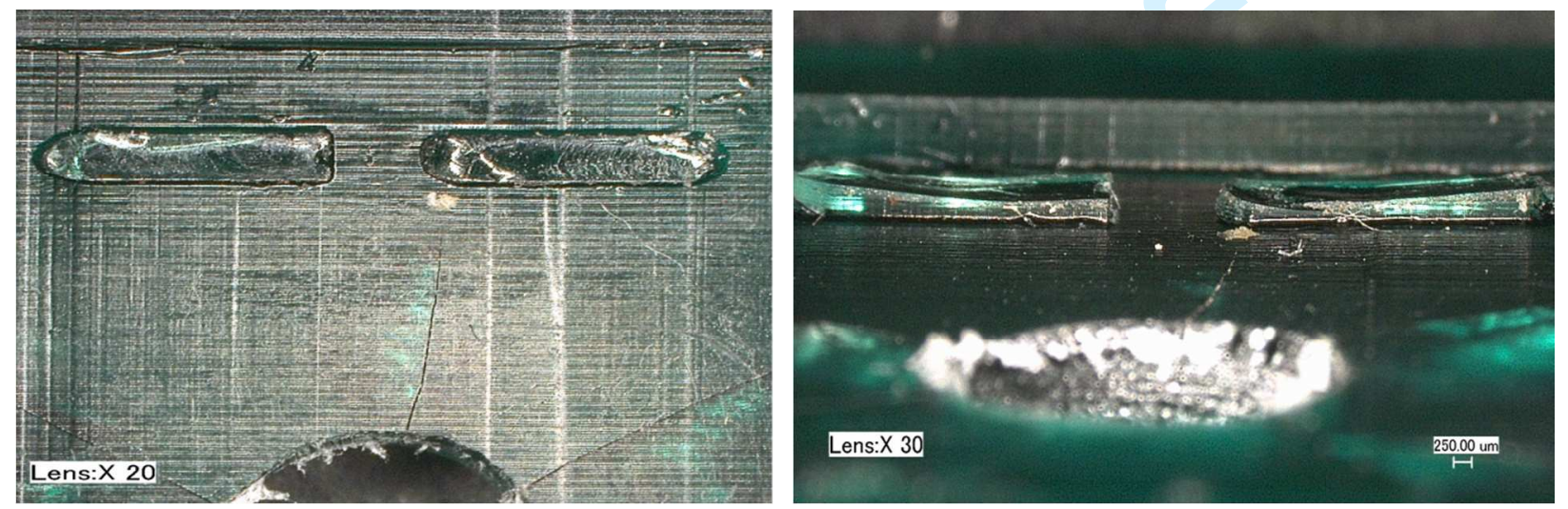
Figure 11. Micro features namely C1and C2 failed after fifth replication: top view (left) and side view of the features (right)

In addition to failure occurred during the filling phase, part ejection, too, caused tool failure. When the part was ejected, the micro features were taken off and remained in the molded part as depicted in Figure 12. This type of failure occurred due to decrease in tool strength at increased temperature and also the stair stepping of the tool. Stair stepping leads to more friction between the tool insert and part. It can be overcome by increasing the cooling time or shortening it. However, early ejection could result in part warpage.

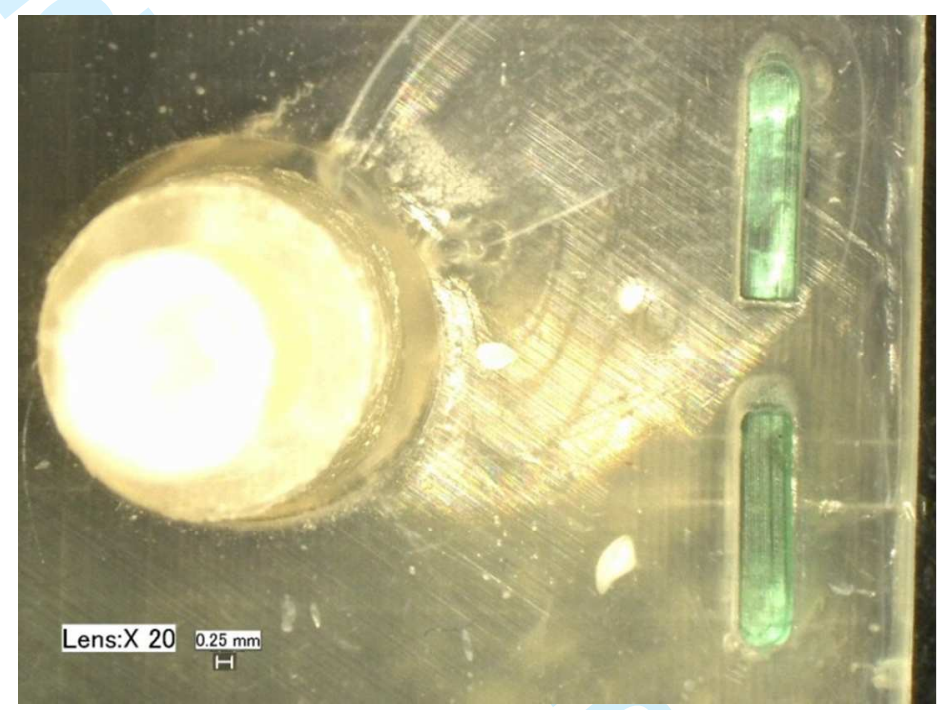

Figure 12. Features taken off from insert 1 after part ejection

Insert 2 had a better performance in terms of flow length in comparison with insert 1 due to thicker features (see Figure 13). However, the quality of replicated parts was not high enough. The features $\mathrm{C} 1$ and $\mathrm{C} 2$ were filled in all the replications and eventually failed within fifth molding. The flow length in C3 increased significantly when the injection time increased from 1 $\mathrm{s}$ to $2 \mathrm{~s}$ (see Figure 14). Also, it could resist the high pressure in comparison with $\mathrm{C} 1$ and $\mathrm{C} 2$. 


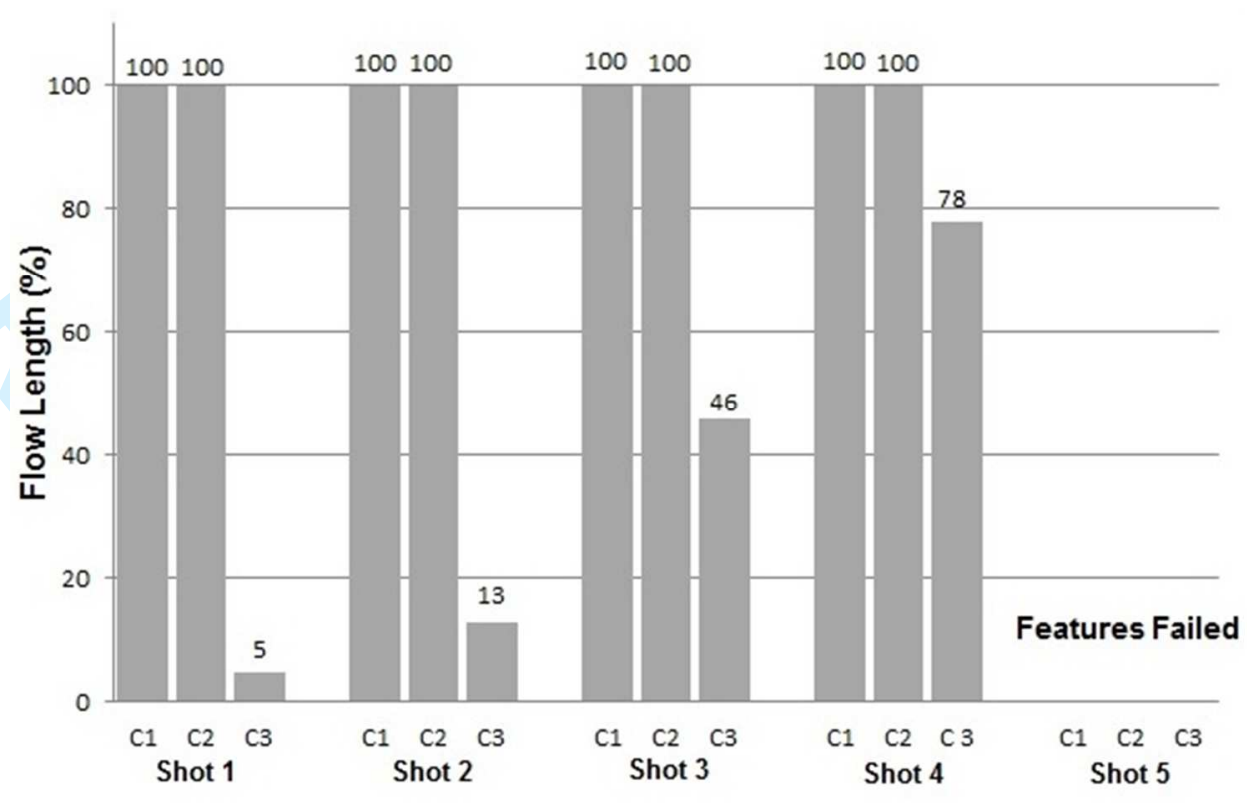

Figure 13. The achieved flow length after each replication with insert 2

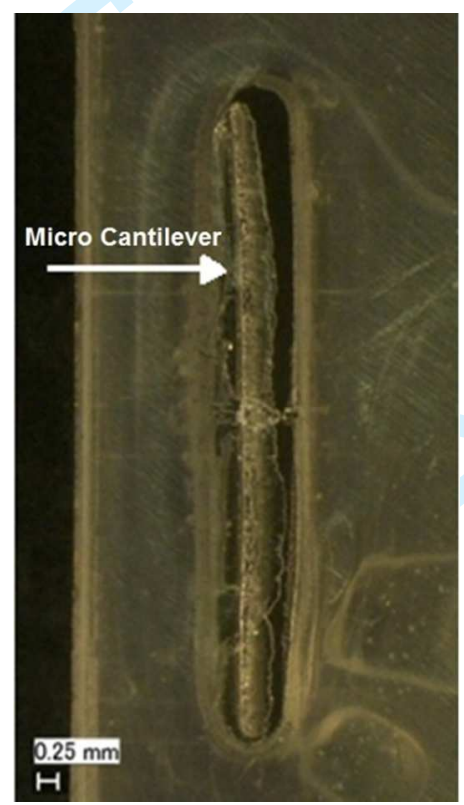

Figure 14. Feature C3 of the replicated part by insert 2, magnification: $x 20$

Once the material is injected into the cavity, a sudden increase of pressure occurs inside the cavity which is considered as the maximum pressure reached. Therefore, it increases the force on the features tremendously. It eventually leads to tool deflection and fracture due to low tensile strength of the tool. Figure 15 shows the possible scenarios which may occur during the filling phase. 


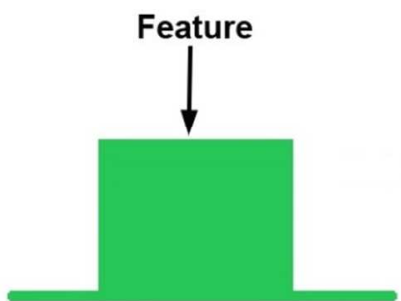

(a)

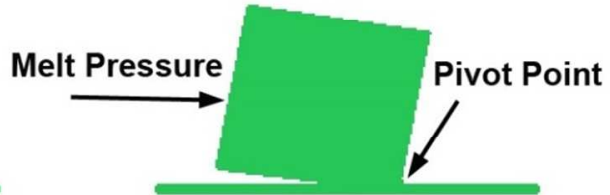

(b)

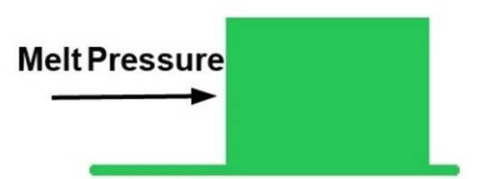

(c)

Figure 15. Schematic view of different scenarios, which may occur during injection. (a) No failure; (b) Flexural failure; (c) Shear failure

The main reason behind the failure of micro features in this study was flexural stresses. It led to instant failure and crack propagation. During the injection, pressure exceeds the mold insert flexural strength so that forces the feature to rotate about its pivot point and ultimately breaks off. For insert 2, features $\mathrm{C} 1$ and $\mathrm{C} 2$ pivoted without being fractured as indicated in Figure 16. The crack propagation was occurred at the face of the features where the flexural stresses were perpendicular to it. Within next cycles, the crack grew and eventually resulted in features failure.

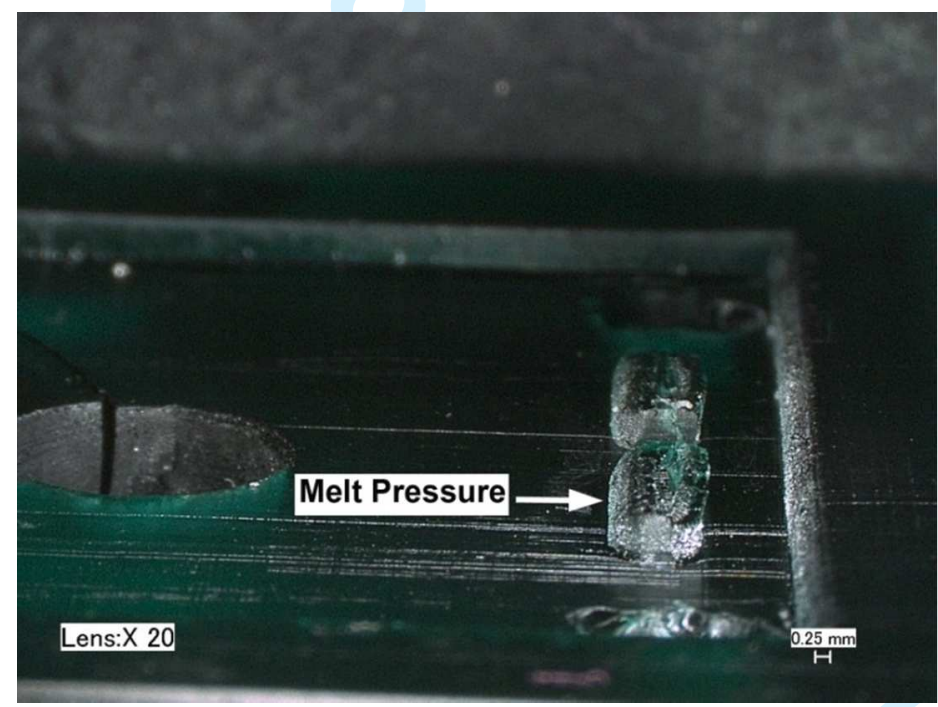

Figure 16. Flexural failure of the $C 1$ and $C 2$ in insert 2

Although in the case of $\mathrm{C} 3$ flexural stress less damaged the feature, the crack propagation phenomenon was observed again. As it was mentioned earlier, insert 2 collaborates features built horizontally where the gravity effect caused unwanted polymerization below them. Therefore, those excessive polymerized materials performed as a kind of support against melt flow for C3 during the molding which eventually led to its resistance against flexural stress. Figure 17 is a microscopic picture taken of the side face of C3 where the flexural stress is perpendicular to it and resulted in crack formation. As a side note, it can be inferred that 
features deflection can also occur within the cooling phase when the shrinkage factor is involved and deforms the micro features more than other regions. Figure 18 shows the damage inside the cavity caused by flexural stress after five shots.

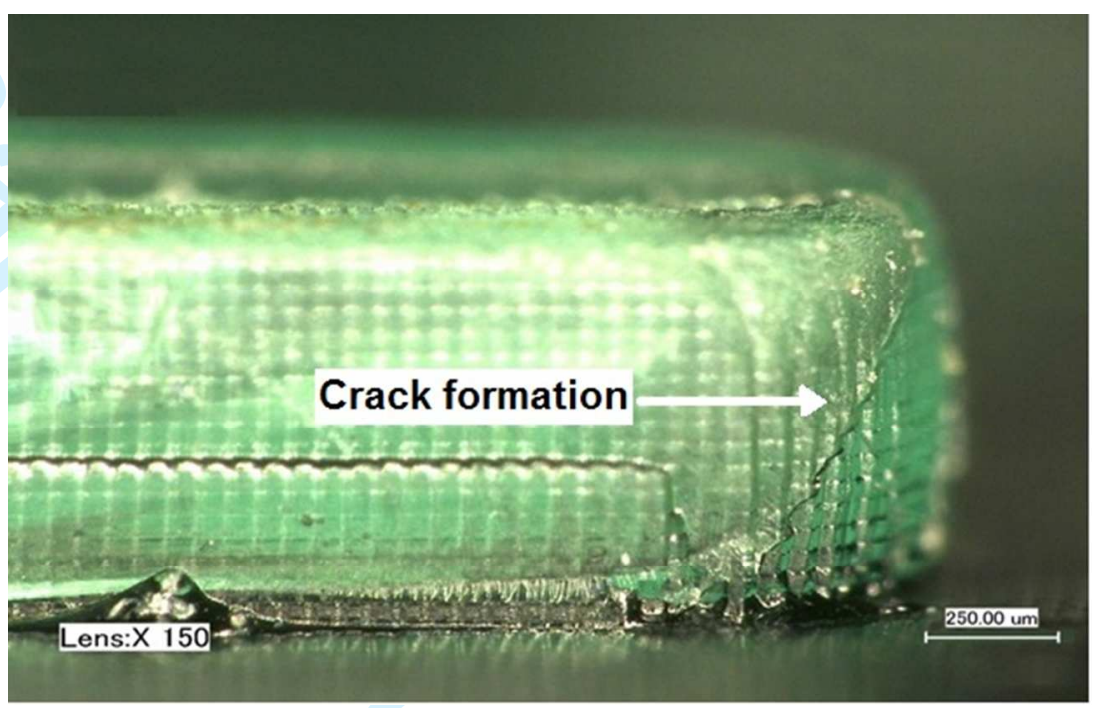

Figure 17. Crack formation in $\mathrm{C} 3$ of insert 2
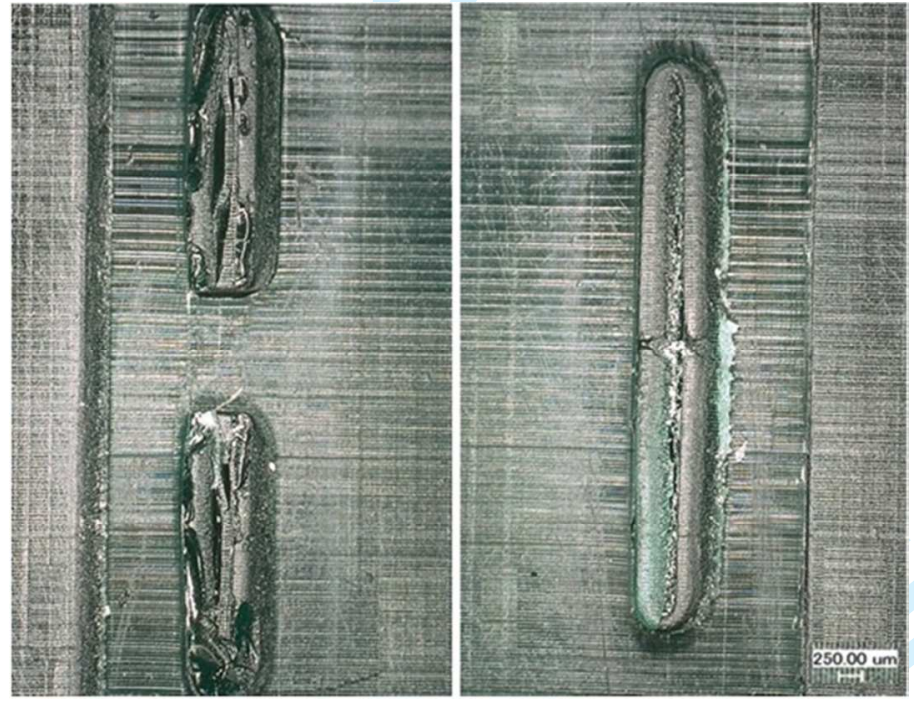

Figure 18. Damaged micro features after the experiments carried out by insert 2; $\mathrm{C} 1$ and $\mathrm{C} 2$ (left) and C3 (right), magnification $=x 30$

\section{Conclusions}

An experimental study was carried out to investigate the feasibility of employing mold inserts fabricated by $\mu \mathrm{SL}$ technique in $\mu \mathrm{IM}$ to replicate small number of micro-cantilevers with thermoplastic polymer materials. The geometrical shape of the tool was assessed to figure out if 
$\mu S L$ is enough accurate for producing mold inserts. Also, the molding performance was analyzed in terms of changes in tool geometry in combination with part quality. The following conclusions can be made based on the obtained results:

- The viability of employing $\mu S L$ inserts to produce micro components with reasonable properties and high aspect ratio was indicated. However, the two tools investigated in this study had different performances in terms of the achieved aspect ratios. On the other hand, the presence of unwanted polymerized material was observed which was due to using inappropriate resin for producing the inserts.

- It was observed that wrong selection of resin for fabricating $\mu S L$ mold inserts resulted in tool failure, not only during the molding process but also when the tool was being produced. It was due to low viscosity of the material which led to unwanted polymerization under the already deposited layers during the build which made the tool inaccurate.

- Investigations indicated that tool life depends on the interaction between injection pressure and temperature. In injection molding with prototype tools low injection pressure favors the process. However, it needs to be compensated by increase in melt temperature to facilitate the flow of material in the cavity. This leads to higher tool temperature. Therefore, injection pressure is one of the significant process factors ruling out the tool and process status.

- Mold feature geometry is another factor directly affecting the number of replications that a mold can make. As the height of the features increases, the tool would be more likely to fail. During the injection, the flexural stresses exerted by melt flow on the face of features perpendicular to flow front was beyond the feature's flexural strength which led to crack formation and propagation and eventually resulted in failure of the features.

- In the case of part ejection, observations showed that the tool must be cooled down sufficiently prior to ejection. Although this increases the cycle time, the tool life is in priority. On the other hand, it should be taken into account that late ejection will increase the ejection forces that may damage the tool. Therefore, cooling time determination is essential to the process. 


\section{References}

De Santis, R., Russo, A., Gloria, A., D'Amora, U., Russo, T., Panseri, S., Sandri, M., Tampieri, A., Marcacci, M., Dediu, V. A., Wilde, C.J. and Ambrosio, L. (2015), "Towards the design of 3D fiber-deposited poly( $\varepsilon$-caprolactone)/iron-doped hydroxyapatite nanocomposite magnetic scaffolds for bone regeneration", Journal of Biomedical Nanotechnology, Vol. 11, pp. 12361246.

Domingos, M., Intranuovo, F., Russo, T., De Santis, R., Gloria, A., Ambrosio, L., Ciurana, J. and Bartolo, P. (2013), "The first systematic analysis of 3D rapid prototyped poly ( $\varepsilon$-caprolactone) scaffolds manufactured through BioCell printing: the effect of pore size and geometry on compressive mechanical behaviour and in vitro hMSC viability", Biofabrication, Vol. 5 No. 4, pp 045004-045017.

Griffiths, C. A., Dimov, S. S., Fischer, S. and Spitzbart, M. (2011), "Micro-stereolithography tools for small-batch manufacture of polymer micro-parts", Journal of Engineering Manufacture, Vol. 226, pp. 708-721.

Griffiths, C. A., Bigot, S., Brousseau, E., Worgull, M., Heckele, M., Nestler, J. and Auerswald, J. (2009), "Investigation of polymer inserts as prototyping tooling for micro injection moulding", International Journal of Advanced Manufacturing Technology, Vol.47, pp. 111-123.

Huaqing, L. (2012), "Study on improving the life of stereolithography injection mold", Advanced Materials Research, Vols. 468-471, pp. 1013-1016.

Jensen, M. F., McCormack, J. E., Helbo, B., Christensen, L. H., Christensen, T. R. and Geschke, O. (2004), "Rapid prototyping of polymer microsystems via excimer laser ablation of polymeric moulds", Lab on a Chip, Vol.4 No.4, pp. 391-395.

Maruo, S. and Ikuta, K. (2002), "Submicron stereolithography for the production of freely movable mechanisms by using single-photon polymerization", Sensors \& Actuators A: Physical, Vol. 100 No. 1, pp. 70-76.

Palmer, A. E. and Colton, J. S. (2000), "Failure mechanisms in stereolithography injection molding tooling", Polymer Engineering and Science, Vol. 40, pp.1395-1397. 
Rahmati, S. and Dickens, Ph. (2007), "Rapid tooling analysis of Stereolithography injection mould tooling", International Journal of Machine Tools \& Manufacture", Vol. 47, pp. 740-747. Vasco, J. C. and Pouzada, S. A. (2013), "A study on microinjection moulding using moulding blocks by additive micromanufacturing", International Journal of Advanced Manufacturing Technology, Vol. 69, pp. 2293-2299.

Yang, H., Segal, J., Turitto, M. and Ratchev, S. (2009), "Rapid manufacturing of micro fluidic devices by microstereolithography", In Proceedings of the International Conference on multimaterial micromanufacture and the International Conference on micro-manufacturing- The Global Conference on micro-manufacture, Karlsruhe, pp. 157- 160.

Zhang, X., Jiang, X. and Sun, C. (1999), "Micro-stereolithography of polymeric and ceramic microstructures", Sensors \& Actuators A: Physical, Vol. 77 No.2, pp. 149-156. 
Figure 1. Test part $362 \times 296 \mathrm{~mm}(72 \times 72$ DPI $)$ 
Figure 2. Mold insert fabricated by $\mu \mathrm{SL}$ technique including three micro cantilevers marked as C1, C2 and C3 $109 \times 121 \mathrm{~mm}(96 \times 96 \mathrm{DPI})$ 


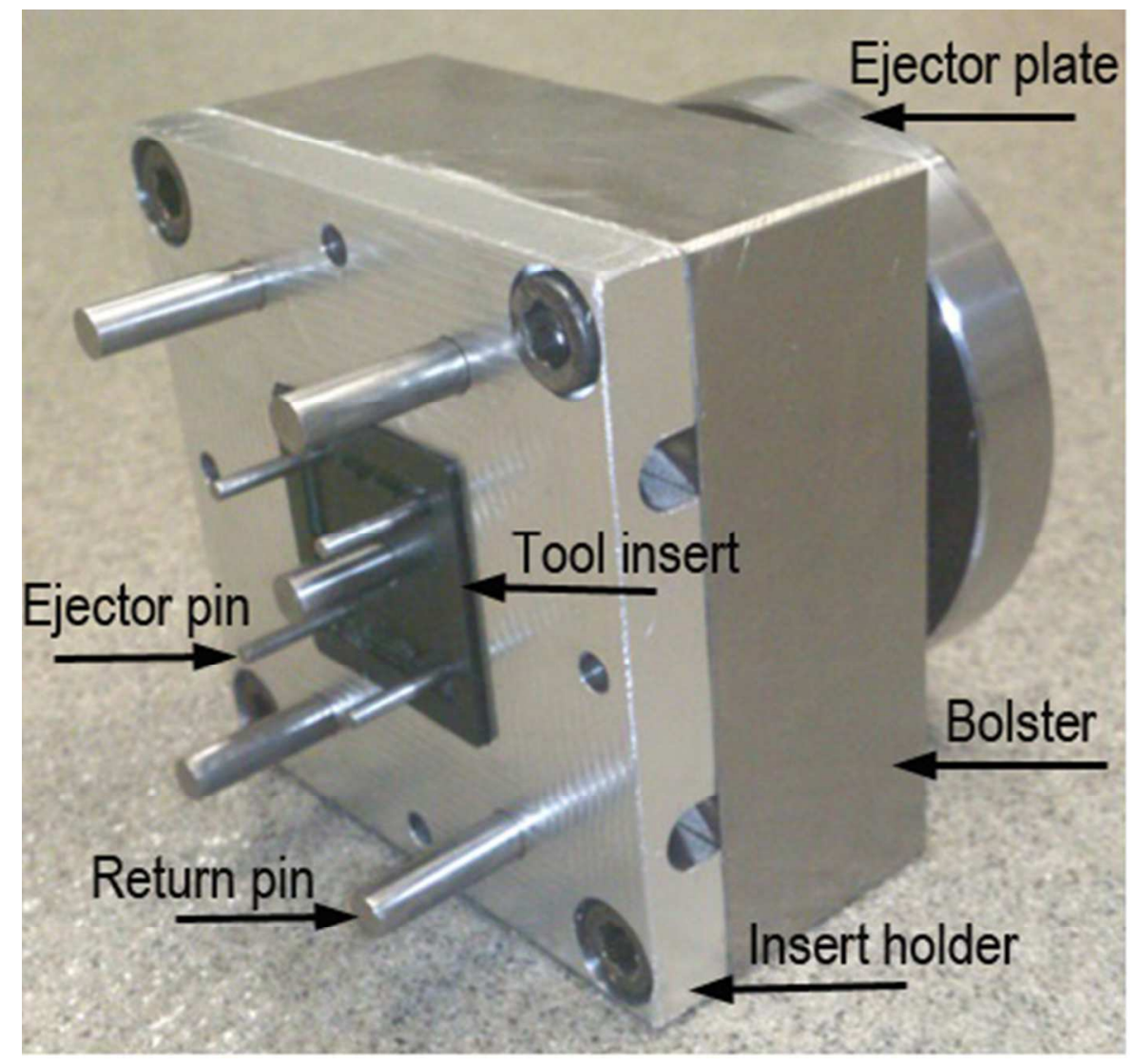

Figure. 3 Mold halves: moving half (left) and fixed half (right) $118 \times 111 \mathrm{~mm}(96 \times 96 \mathrm{DPI})$ 
Figure 4. Insert 2 with features built horizontally (left) and insert 3 with features built vertically (right) $117 \times 112 \mathrm{~mm}(96 \times 96 \mathrm{DPI})$ 


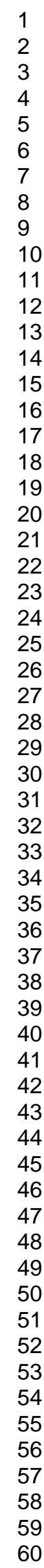

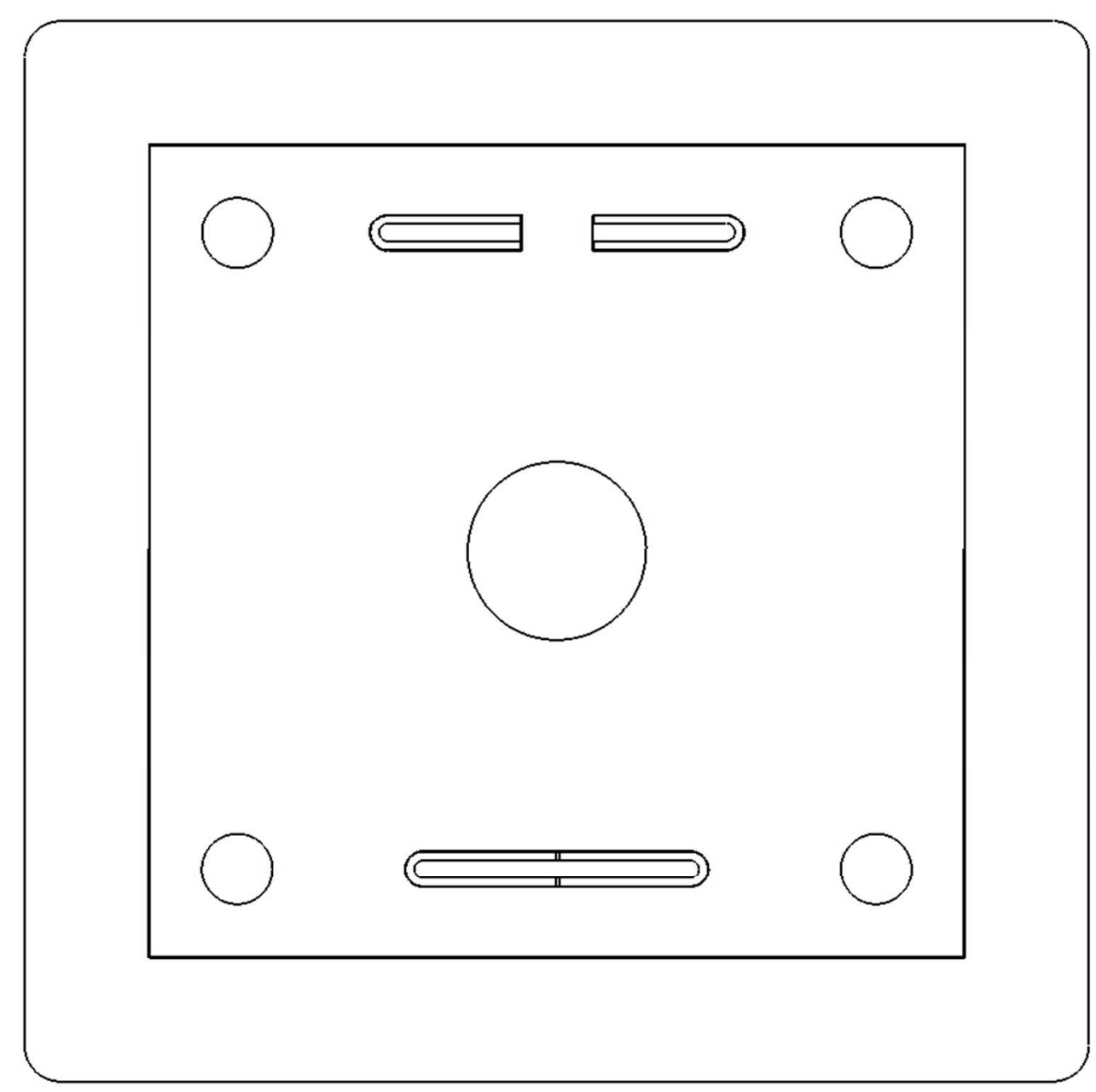

Figure 4. (a) Insert 2 with features built horizontally and (b) insert 3 with features built vertically $332 \times 327 \mathrm{~mm}(72 \times 72 \mathrm{DPI})$ 


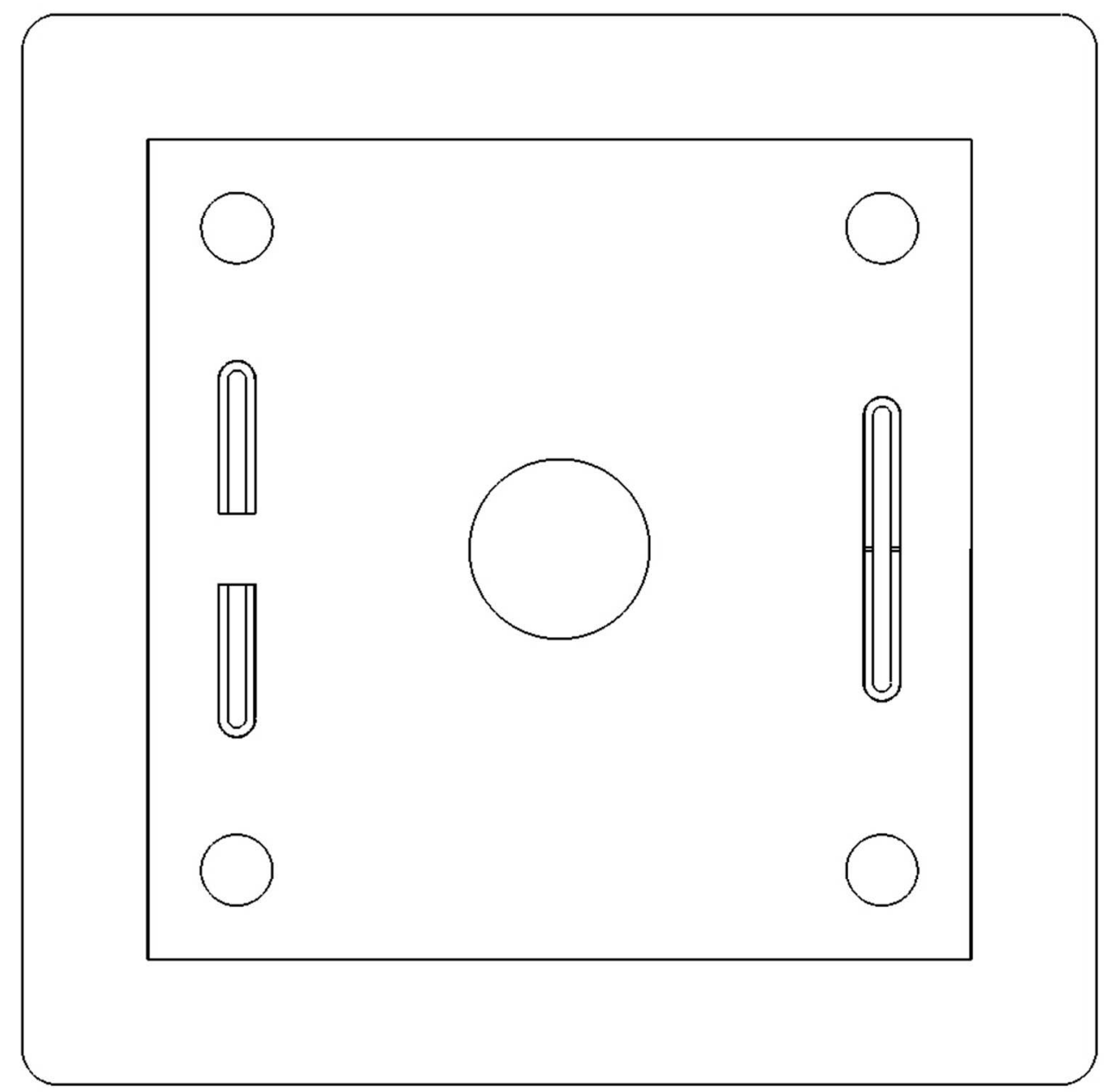

Figure 4. Insert 2 with features built horizontally (left) and insert 3 with features built vertically (right) $332 \times 327 \mathrm{~mm}(72 \times 72$ DPI $)$ 


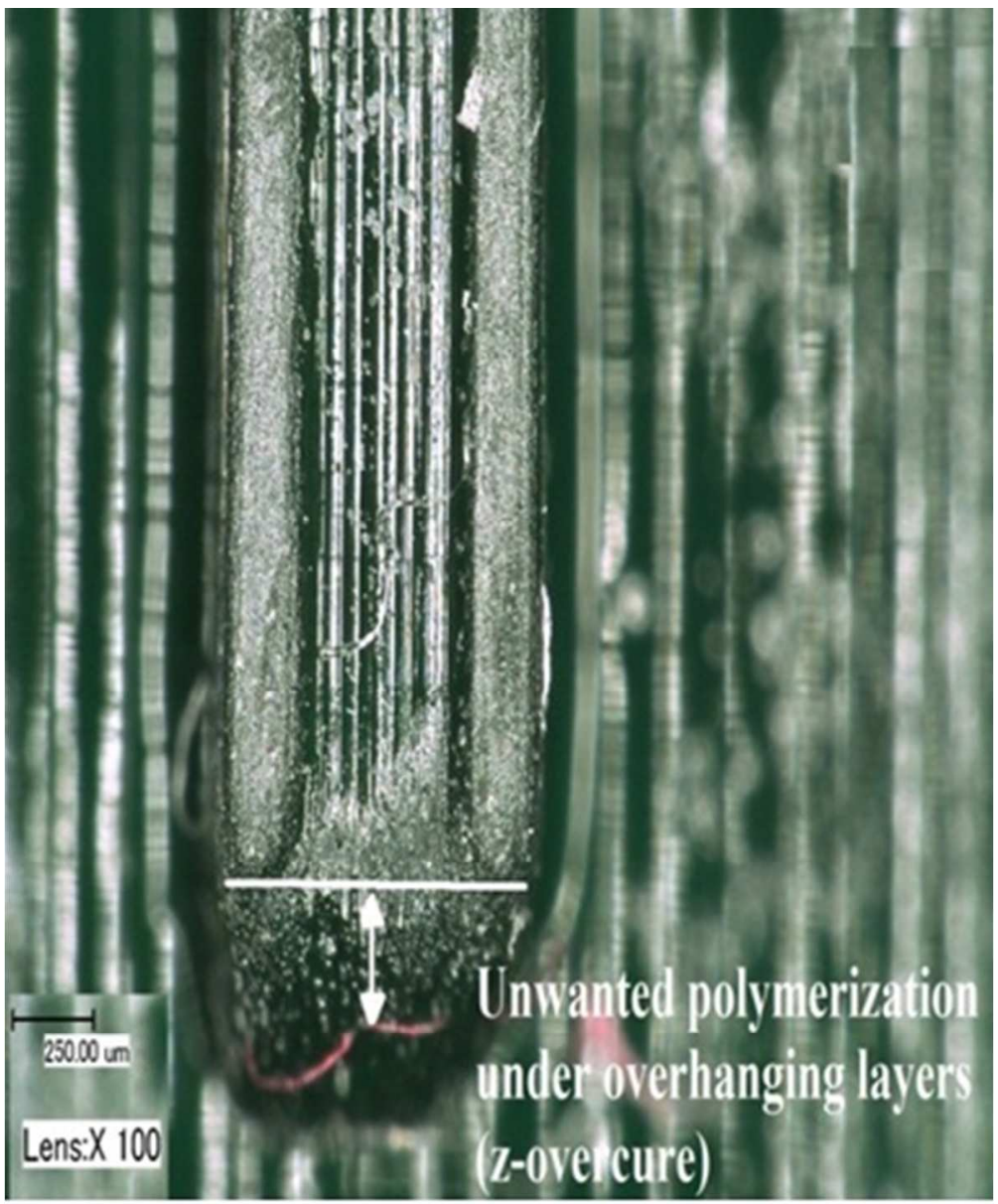

Figure 5. Comparison of channels with unwanted polymerization (left) and without it (right) $101 \times 122 \mathrm{~mm}(96 \times 96 \mathrm{DPI})$ 


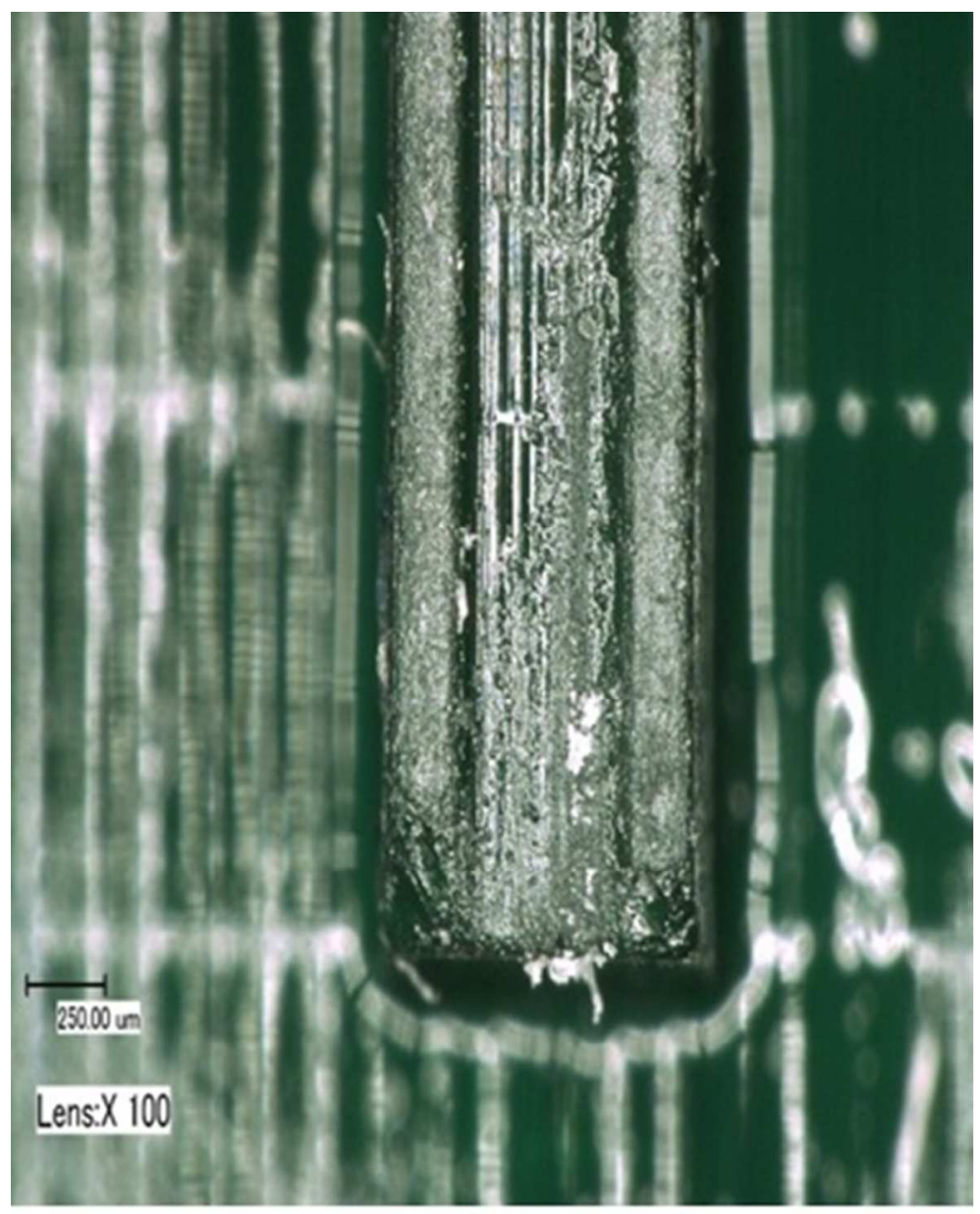

Figure 5. Comparison of channels with unwanted polymerization (left) and without it (right) $99 \times 124 \mathrm{~mm}(96 \times 96 \mathrm{DPI})$ 

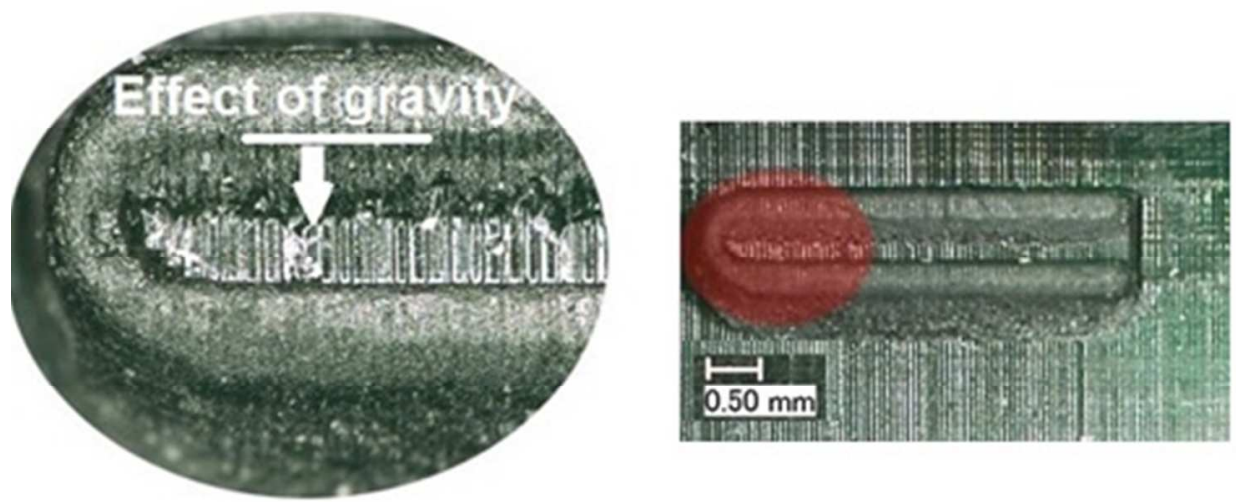

Figure 6. Increased effect of gravity in micro features built horizontally.

$125 \times 52 \mathrm{~mm}(96 \times 96 \mathrm{DPI})$ 
1

2

3

4

5

6

7

8

9

10

11

12

13

14

15

16

17

18

19

20

21

22

23

24

25

26

27

28

29

30

31

32

33

34

35

36

37

38

39

40

41

42

43

44

45

46

47

48

49

50

51

52

53

54

55

56

57

58

59

60

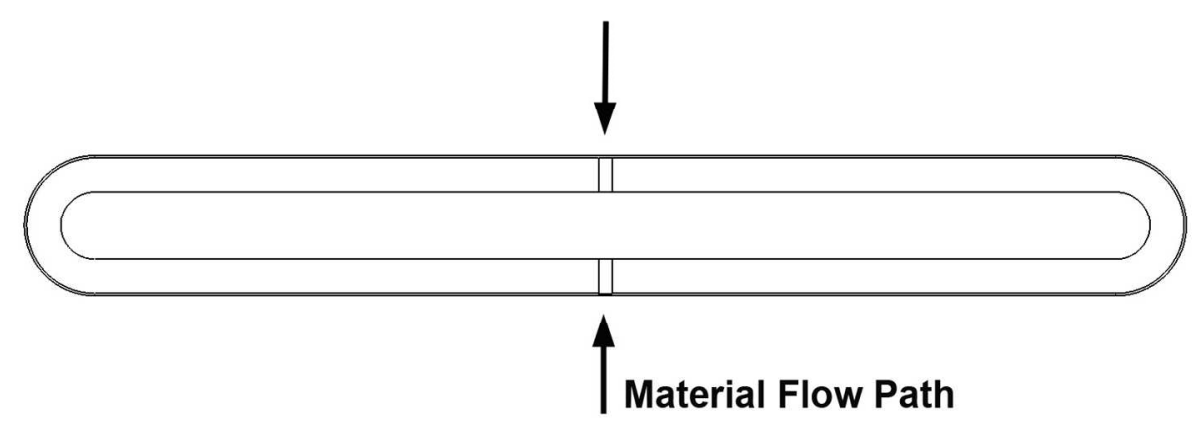

Figure 7. Flow paths of C3 inside insert 3, sketch of micro feature (top) and SEM image of micro feature (bottom)

$582 \times 191 \mathrm{~mm}(72 \times 72 \mathrm{DPI})$ 
Figure 7. Flow paths of $\mathrm{C} 3$ inside insert 3, sketch of micro feature (top) and SEM image of micro feature (bottom)

$122 \times 112 \mathrm{~mm}$ (96 x 96 DPI) 


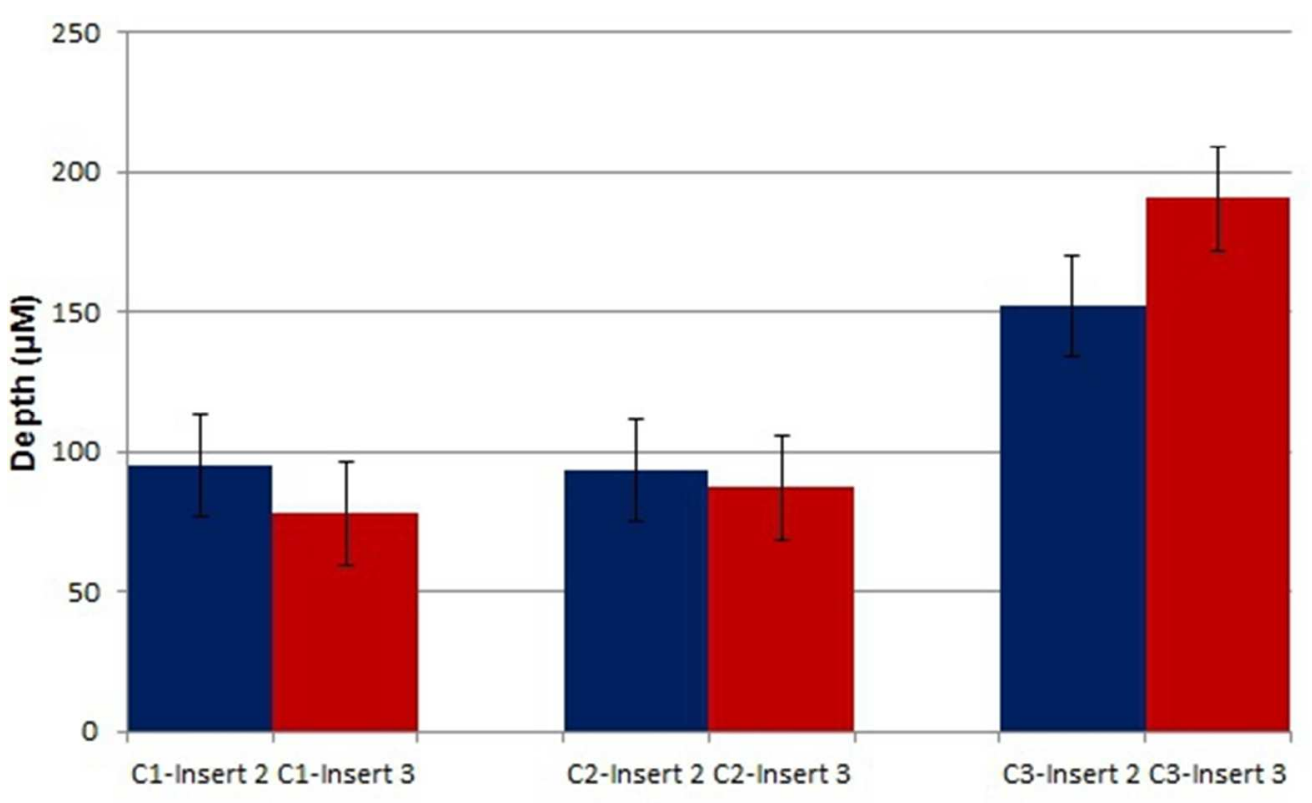

Figure 8. Depth measurements of micro features in insert 2 and insert 3 $146 \times 89 \mathrm{~mm}(96 \times 96 \mathrm{DPI})$ 


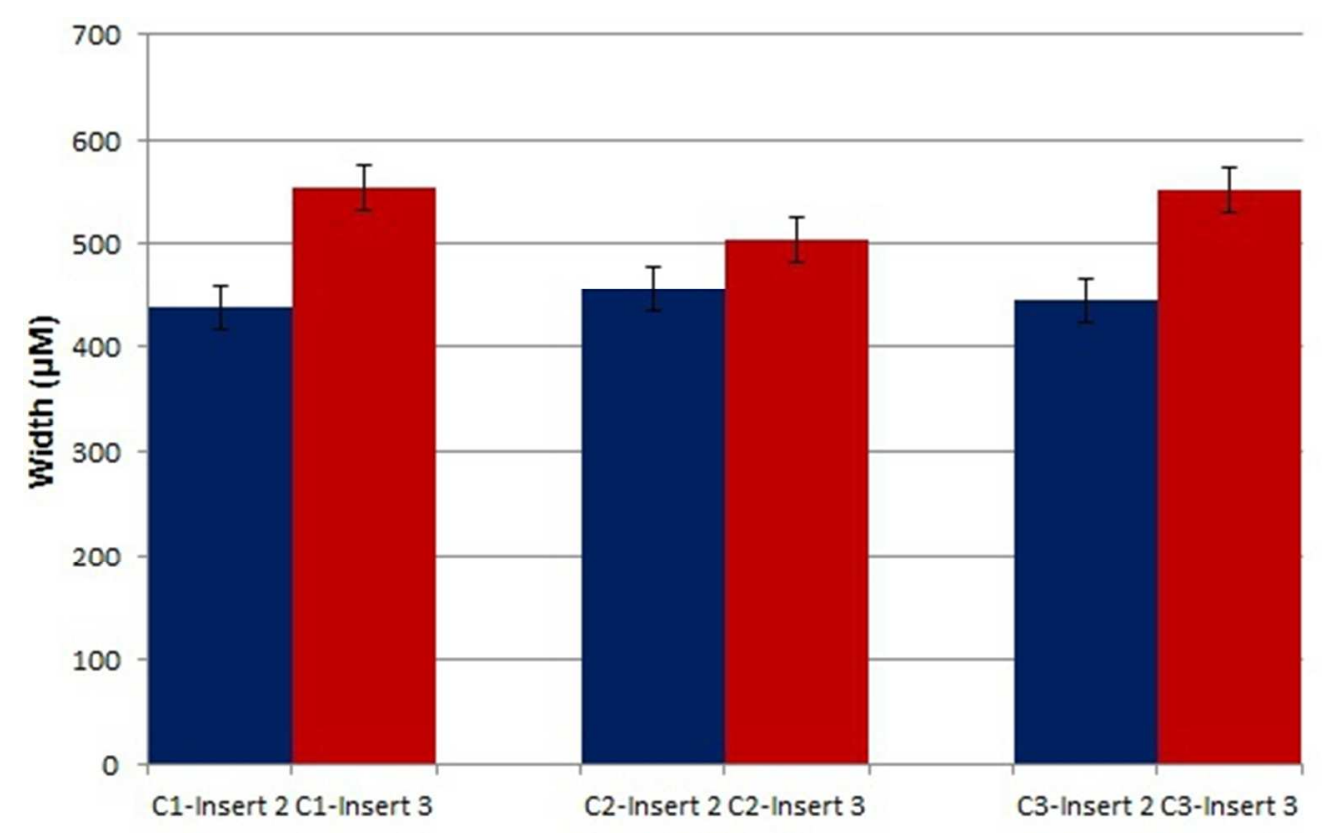

Figure 9. Width measurements of micro features in insert 2 and insert 3 $146 \times 91 \mathrm{~mm}(96 \times 96 \mathrm{DPI})$ 


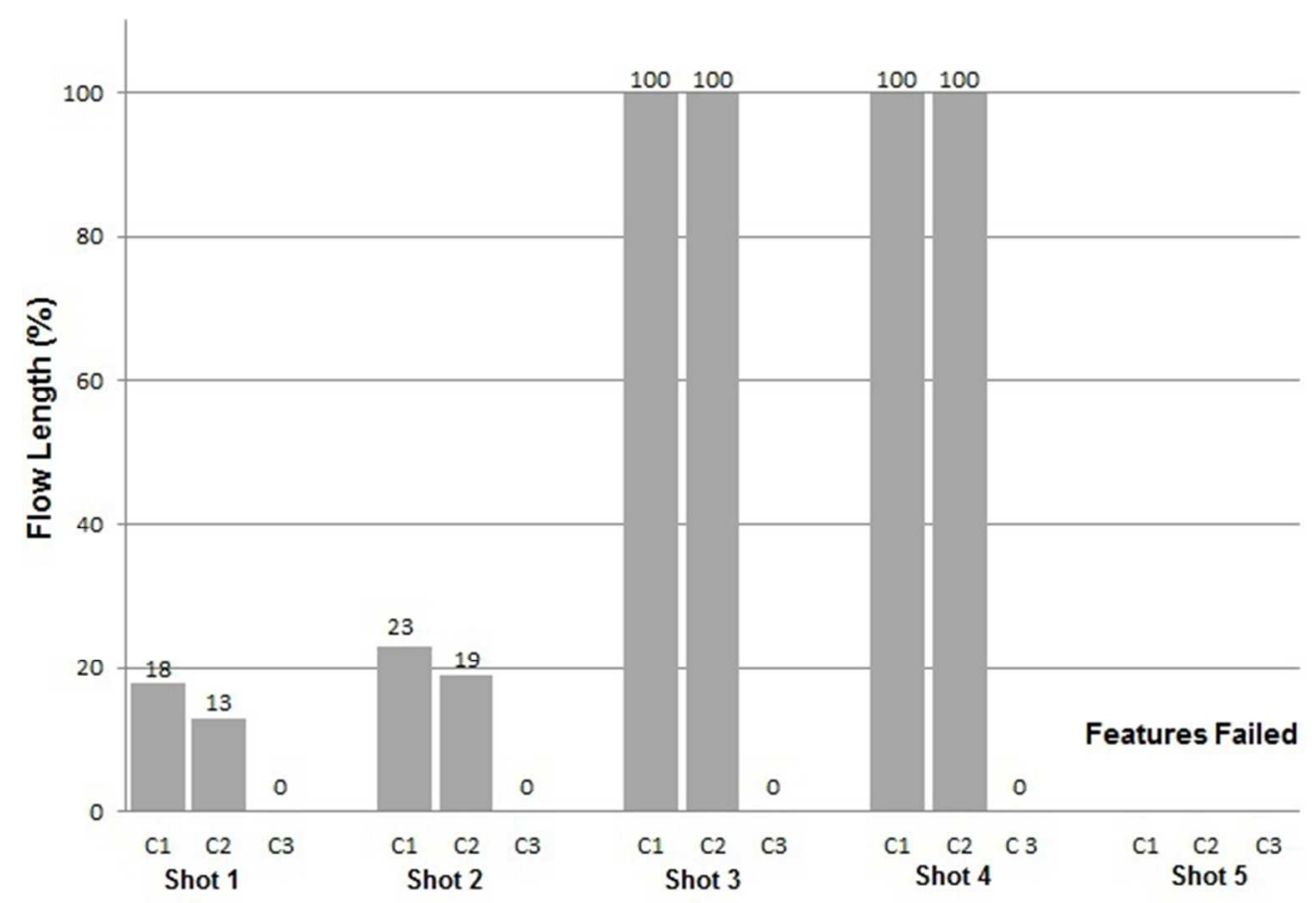

Figure 10. The achieved flow length after each replication with insert 1.

$175 \times 124 \mathrm{~mm}(96 \times 96 \mathrm{DPI})$ 


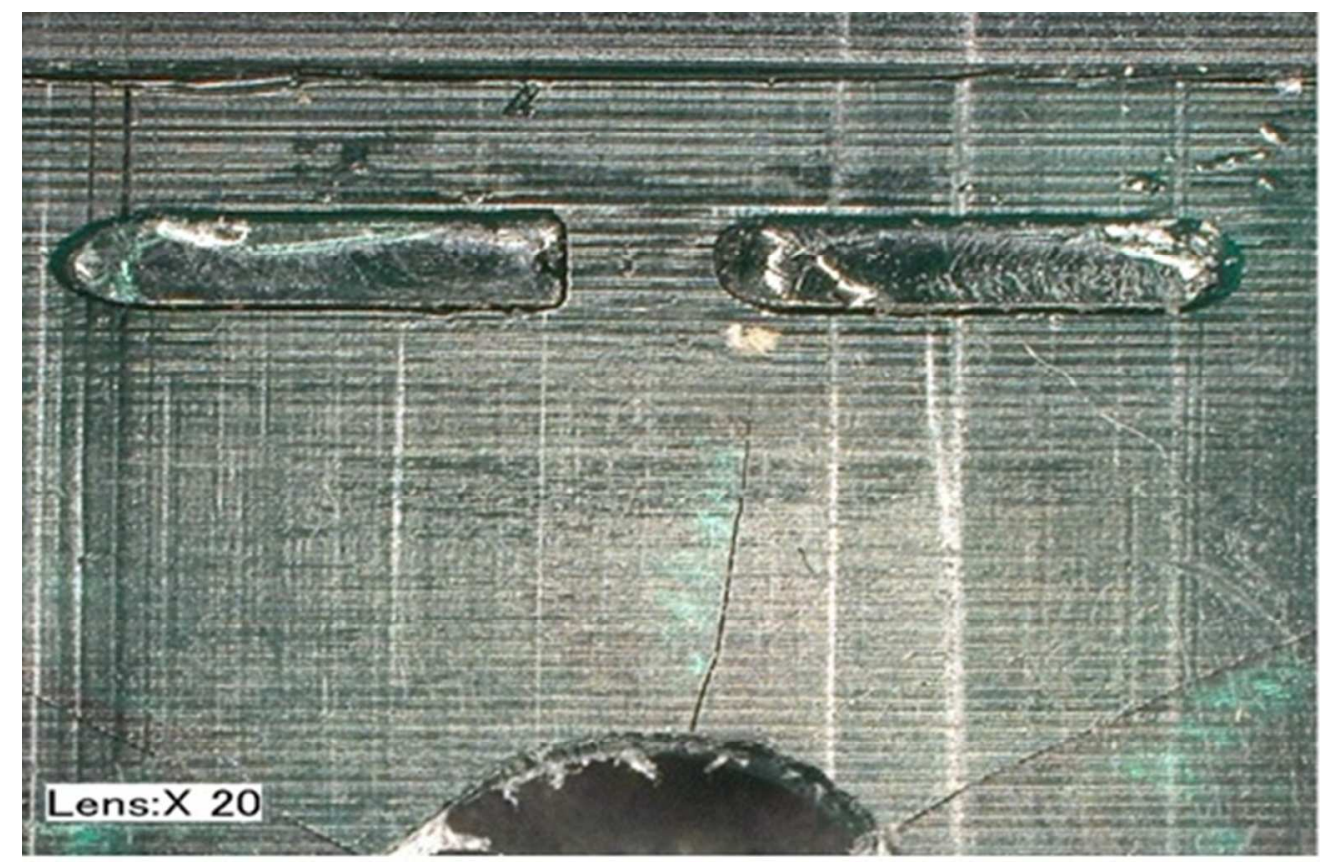

Figure 11. Micro features namely $\mathrm{C} 1$ and $\mathrm{C} 2$ failed after fifth replication: top view (left) and side view of the features (right)

$138 \times 90 \mathrm{~mm}(96 \times 96 \mathrm{DPI})$ 
Figure 11. Micro features namely C1and C2 failed after fifth replication: top view (left) and side view of the features (right)

$146 \times 94 \mathrm{~mm}(96 \times 96 \mathrm{DPI})$ 


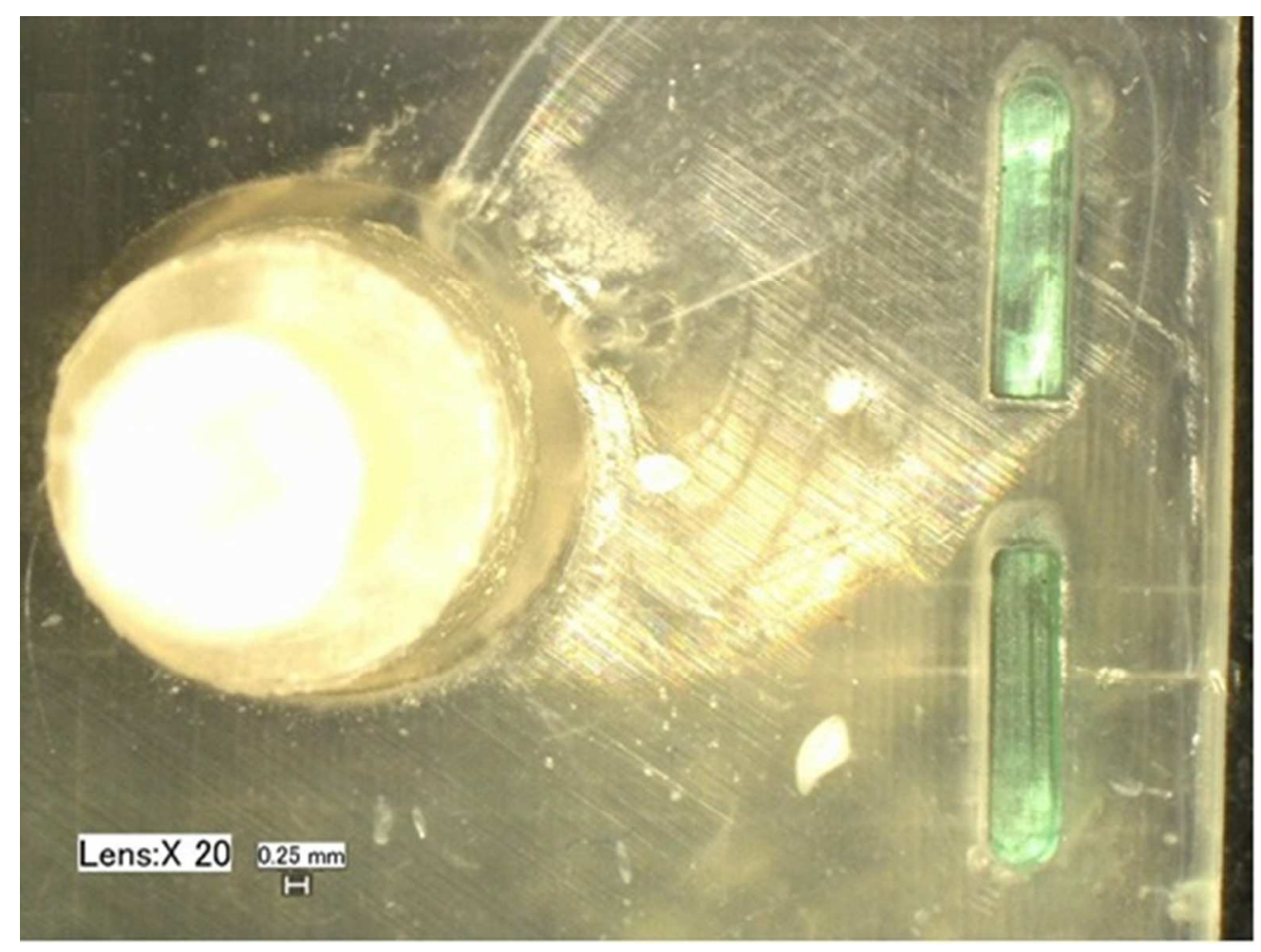

Figure 12. Features taken off from insert 1 after part ejection $138 \times 104 \mathrm{~mm}(96 \times 96$ DPI $)$ 


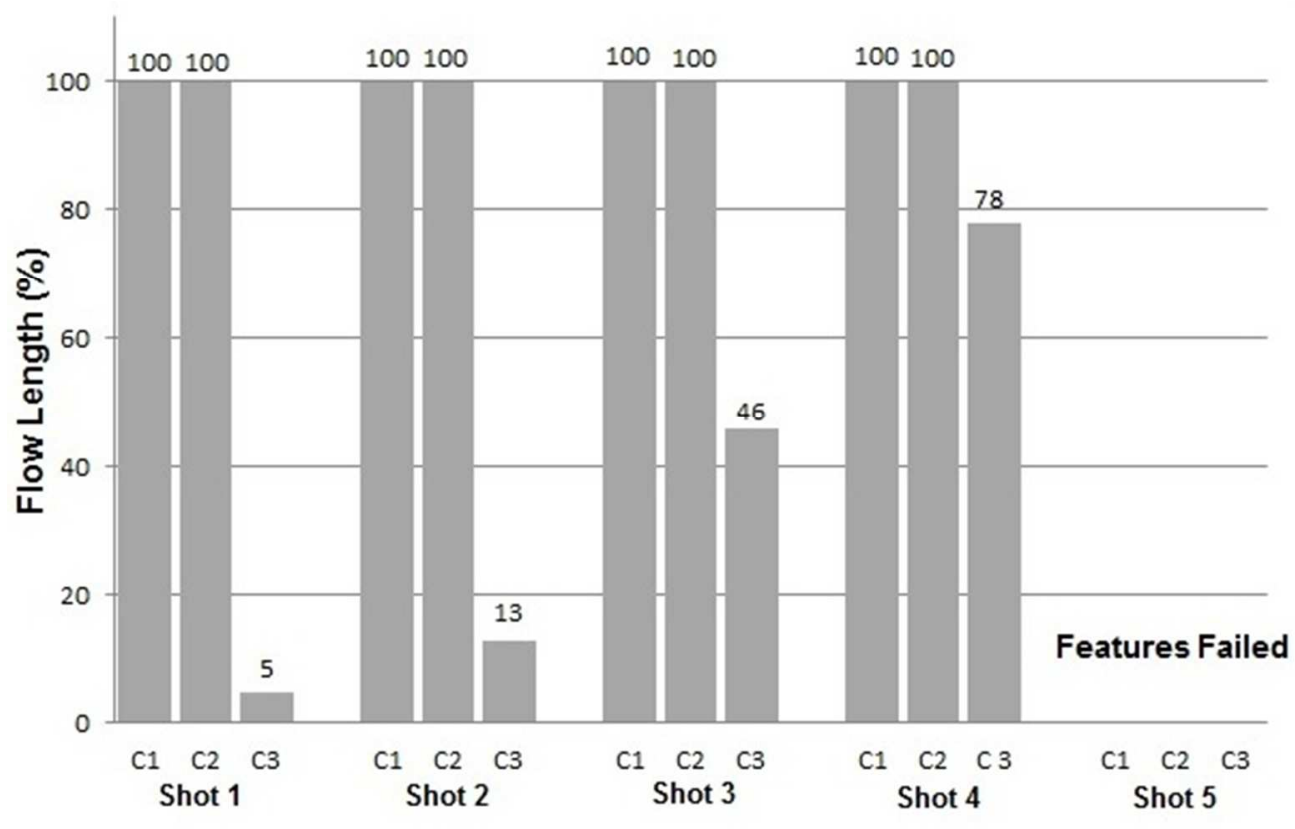

Figure 13. The achieved flow length after each replication with insert 2 $160 \times 102 \mathrm{~mm}(96 \times 96$ DPI) 


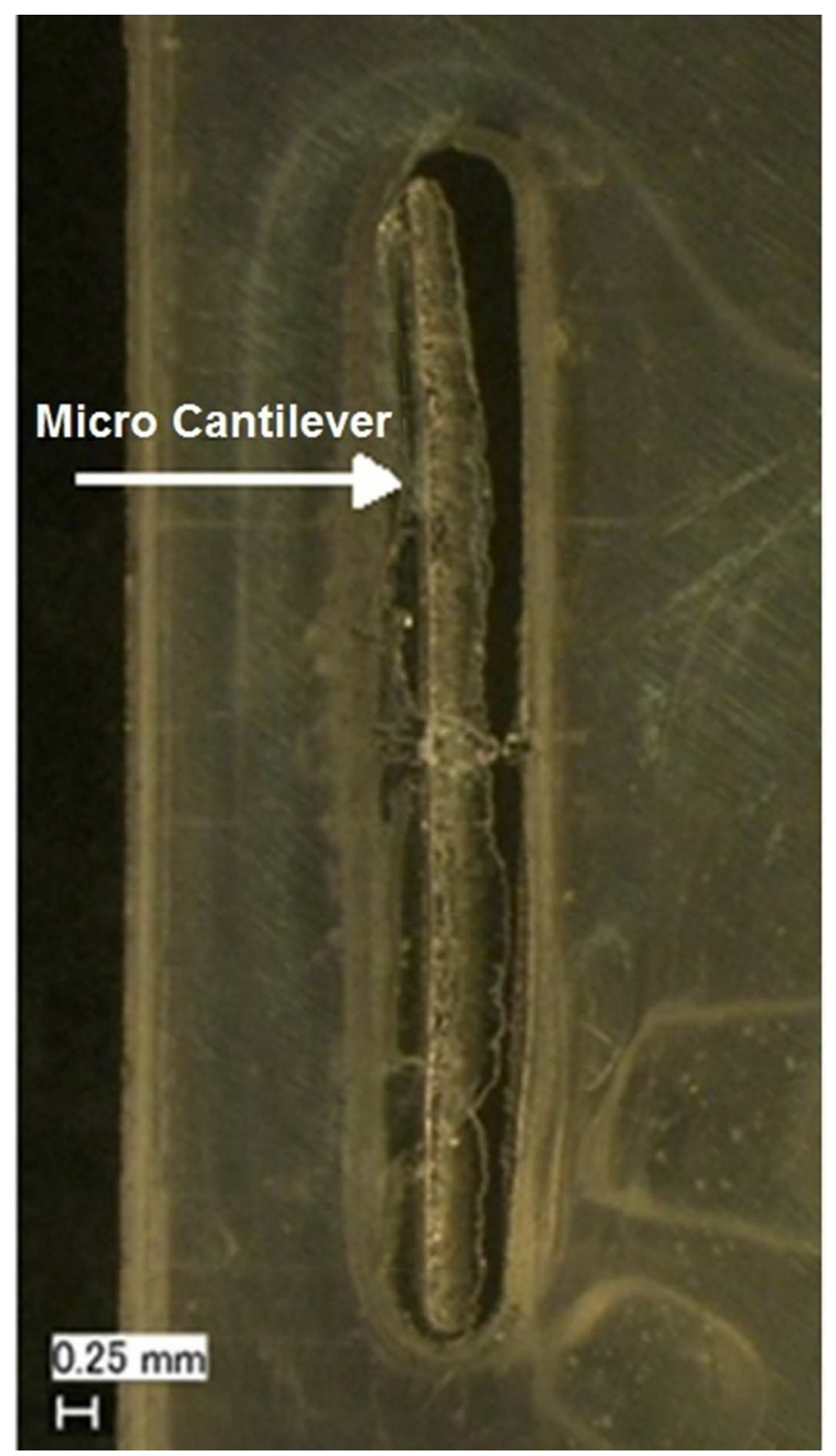

Figure 14. Feature $\mathrm{C} 3$ of the replicated part by insert 2, magnification: $\times 20$ $112 \times 198 \mathrm{~mm}(96 \times 96 \mathrm{DPI})$ 


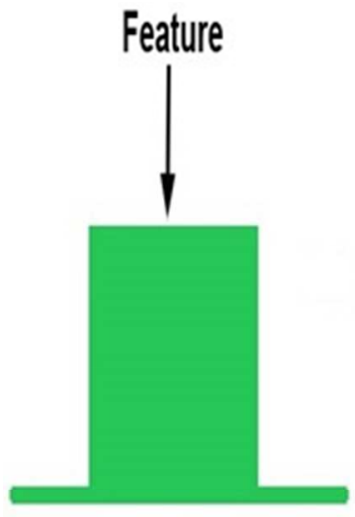

(a)

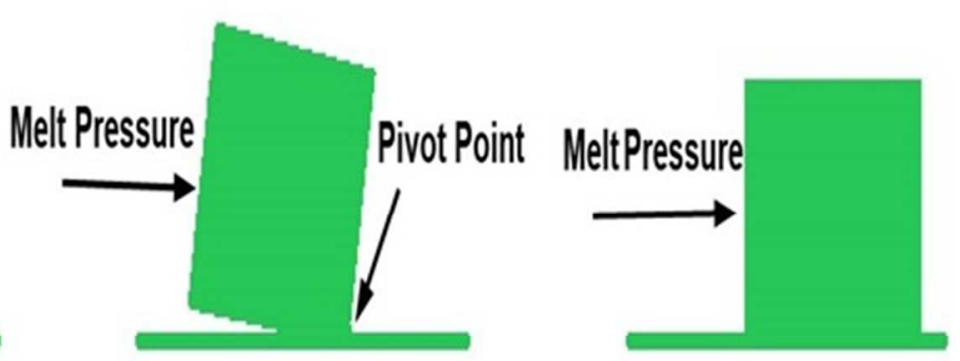

(b)

(c)

Figure 15. Schematic view of different scenarios, which may occur during injection. (a) No failure; (b) Flexural failure; (c) Shear failure 


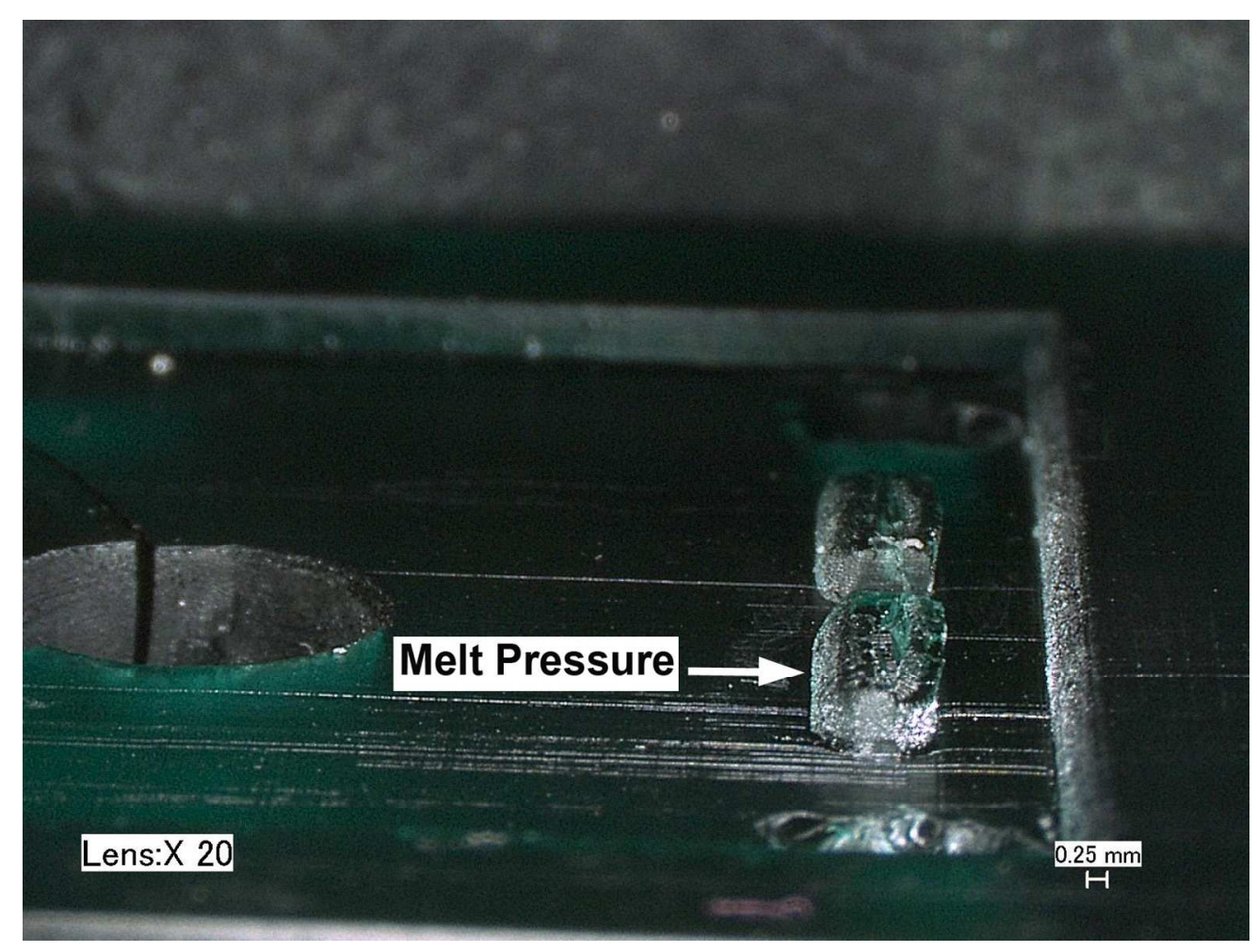

Figure 16. Flexural failure of the $\mathrm{C} 1$ and $\mathrm{C} 2$ in insert 2. $564 \times 423 \mathrm{~mm}(72 \times 72$ DPI $)$ 


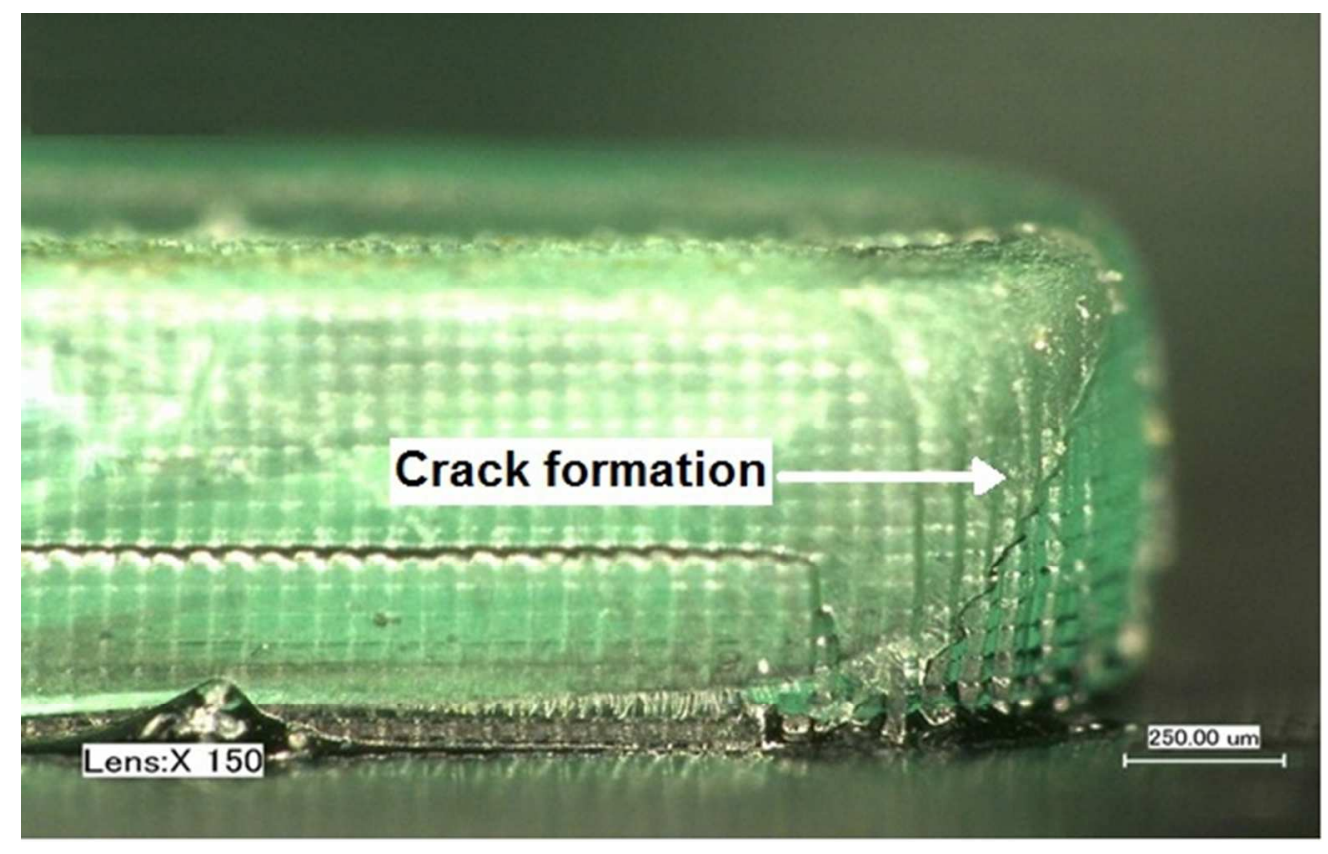

Figure 17. Crack formation in C3 of insert 2 $164 \times 104 \mathrm{~mm}(96 \times 96 \mathrm{DPI})$ 

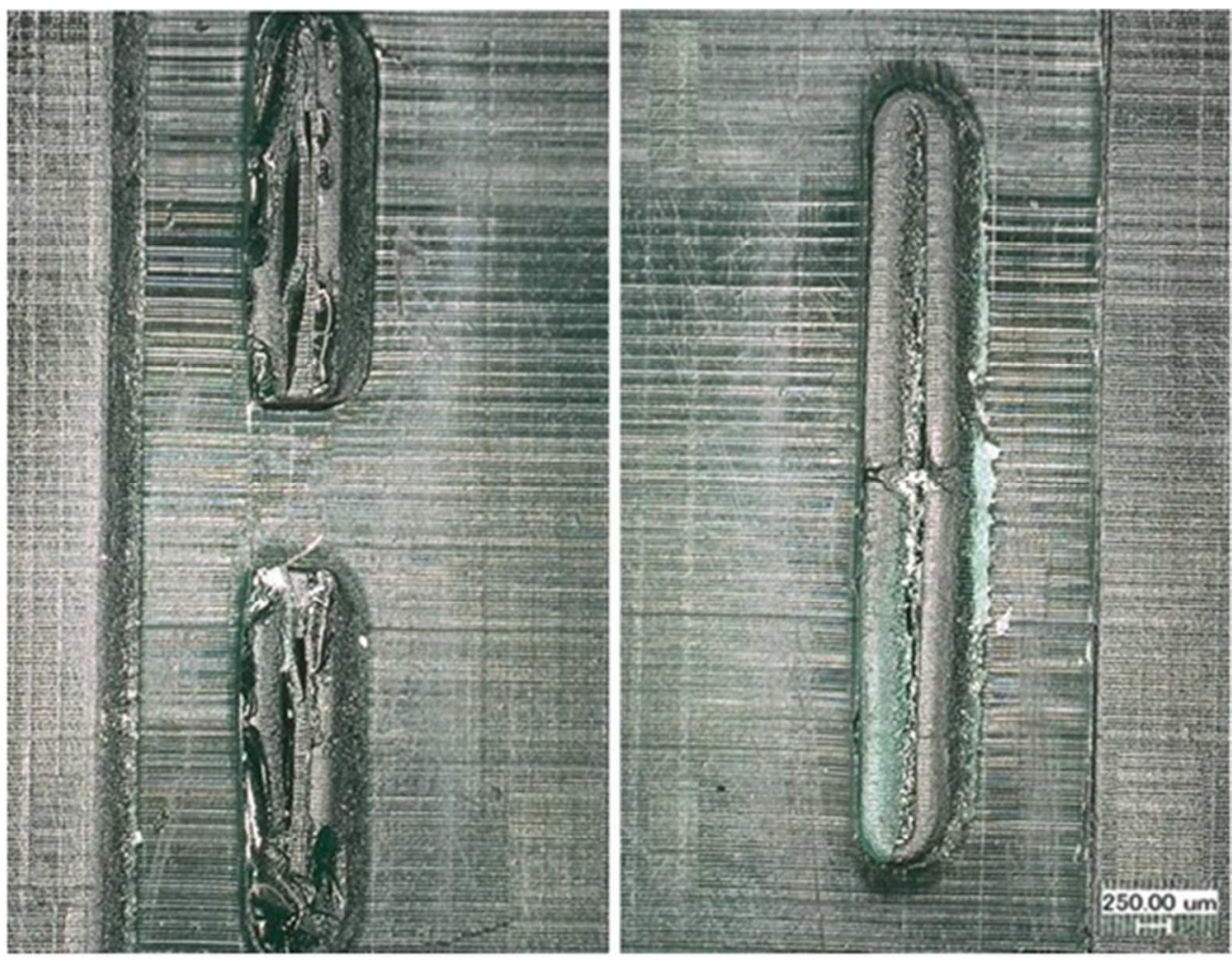

Damaged micro features after the experiments carried out by insert 2; C1 and C2 (left) and C3 (right), magnification $=x 30$

$150 \times 116 \mathrm{~mm}(96 \times 96 \mathrm{DPI})$ 
Table 1. Polymer materials properties

\begin{tabular}{cc}
\hline Material & SABIC 56M10 \\
\hline Category & Polypropylene \\
Structure & Semi-Crystalline \\
Transition temperature & 150 \\
{$\left[{ }^{\circ} \mathrm{C}\right]$} & \\
Ejection temperature $\left[{ }^{\circ} \mathrm{C}\right]$ & 80 \\
Specific heat $[\mathrm{J} / \mathrm{kg}-\mathrm{C}]$ & 2750 \\
Thermal conductivity & 0.18 \\
{$[\mathrm{~W} / \mathrm{m}-\mathrm{C}]$} & 481 \\
Shear modulus $[\mathrm{MPa}]$ & \\
\hline
\end{tabular}


1

2

3

4

5

6

7

8

9

10

11

12

13

14

15

16

17

18

19

20

21

22

23

24

25

26

27

28

29

30

31

32

33

34

35

36

37

38

39

40

41

42

43

44

45

46

47

48

49

50

51

52

53

54

55

56

57

58

59

60

Table 2. Properties of mold inserts material

\begin{tabular}{ll}
\hline Material & VisiJet FTX Green \\
\hline Colour & Dark Green \\
Density $\left(25^{\circ} \mathrm{C}\right)$ & $1.04 \mathrm{~g} / \mathrm{cm}^{3}$ \\
Tensile Strength & $30 \mathrm{MPa}$ \\
Tensile Modulus & $1700 \mathrm{MPa}$ \\
Flexural Stress & $40 \mathrm{MPa}$ \\
\hline
\end{tabular}


Table 3. Molding settings

\begin{tabular}{|c|c|c|c|c|}
\hline \multirow[b]{2}{*}{ Test } & \multirow[b]{2}{*}{ Material } & \multicolumn{3}{|c|}{ Process settings } \\
\hline & & $\mathrm{T}_{\mathrm{b}}\left[{ }^{\circ} \mathrm{C}\right]$ & $t_{i}[s]$ & $\mathrm{D}[\mu \mathrm{m}]$ \\
\hline $\begin{array}{c}\text { Insert } \\
1\end{array}$ & PP & 270 & 1 & 30 \\
\hline $\begin{array}{c}\text { Insert } \\
2\end{array}$ & PP & 270 & 1 & 120 \\
\hline
\end{tabular}

